\title{
Silica coatings in the Ka'u Desert, Hawaii, a Mars analog terrain: A micromorphological, spectral, chemical, and isotopic study
}

\author{
Steven M. Chemtob, ${ }^{1}$ Bradley L. Jolliff, ${ }^{2}$ George R. Rossman, ${ }^{1}$ John M. Eiler, ${ }^{1}$ \\ and Raymond E. Arvidson ${ }^{2}$ \\ Received 27 July 2009; revised 9 October 2009; accepted 2 November 2009; published 1 April 2010.
}

[1] High-silica materials have been observed on Mars, both from orbit by the CRISM spectrometer and in situ by the Spirit rover at Gusev Crater. These observations potentially imply a wet, geologically active Martian surface. To understand silica formation on Mars, it is useful to study analogous terrestrial silica deposits. We studied silica coatings that occur on the 1974 Kilauea flow in the Ka'u Desert, Hawaii. These coatings are typically composed of two layers: a $\sim 10 \mu$ m layer of amorphous silica, capped by a $\sim 1 \mu \mathrm{m}$ layer of Fe-Ti oxide. The oxide coating is composed of $\sim 100 \mathrm{~nm}$ spherules, suggesting formation by chemical deposition. Raman spectroscopy indicates altered silica glass as the dominant phase in the silica coating and anatase and rutile as dominant phases in the Fe-Ti coating; jarosite also occurs within the coatings. Oxygen isotopic contents of the coatings were determined by secondary ion mass spectrometry (Cameca $7 \mathrm{f}$ and

NanoSIMS). The measured values, $\delta^{18} \mathrm{O}_{\mathrm{Fe}-\mathrm{Ti}}=14.6 \pm 2.1 \%$, and $\delta^{18} \mathrm{O}_{\text {silica }}=12.1 \pm 2.2 \%$ (relative to SMOW), are enriched in ${ }^{18} \mathrm{O}$ relative to the basalt substrate. The observations presented are consistent with a residual formation mechanism for the silica coating. Acid-sulfate solutions leached away divalent and trivalent cations, leaving a silicaenriched layer behind. Micrometer-scale dissolution and reprecipitation may have also occurred within the coatings. Chemical similarities between the Hawaiian samples and the high-silica deposits at Gusev suggest that the Martian deposits are the product of extended periods of similar acid-sulfate leaching.

Citation: Chemtob, S. M., B. L. Jolliff, G. R. Rossman, J. M. Eiler, and R. E. Arvidson (2010), Silica coatings in the Ka'u Desert, Hawaii, a Mars analog terrain: A micromorphological, spectral, chemical, and isotopic study, J. Geophys. Res., 115, E04001, doi:10.1029/2009JE003473.

\section{Introduction}

[2] Surface coatings on rocks are ubiquitous on Earth, and have been observed on the surface of Mars [Christensen et al., 2004]. Coatings record physical and chemical interactions between the substrate and the surrounding environment [Dorn, 1998]. Silica coatings are a common type of surface deposit that forms on Earth in a variety of geologic environments through a variety of mechanisms. Most silica coatings form in semiarid environments, such as Hawaii and the Snake River Plain [Farr and Adams, 1984], but such coatings can also form in hydrothermal and epithermal spring settings [Rodgers et al., 2002]. Silica is also a common component of desert varnish [Perry et al., 2006]. Documented mechanisms of silica coating formation include dissolution of windblown particulates and reprecipitation of silica [Curtiss et al., 1985], leaching of divalent and trivalent

\footnotetext{
${ }^{1}$ Division of Geological and Planetary Sciences, California Institute of Technology, Pasadena, California, USA.

${ }^{2}$ Department of Earth and Planetary Sciences, Washington University in Saint Louis, Saint Louis, Missouri, USA.

Copyright 2010 by the American Geophysical Union. 0148-0227/10/2009JE003473
}

cations from volcanic glass [Minitti et al., 2007], growth in solution followed by gravity deposition [Darragh et al., 1966], and vapor deposition [Gu et al., 2002]. The chemistry and morphology of silica deposits can be influenced by the deposition mechanism [Rodgers et al., 2002].

[3] Coatings influence spectral measurements in remote sensing and in situ analyses. Thin silica coatings have been shown to mask the spectral signature of a basaltic substrate in thermal infrared analyses [Crisp et al., 1990; Kraft et al., 2003] and visible and near-infrared reflectance analyses [Abrams et al., 1991; Seelos et al., 2010]. Although spectral analyses of coated surfaces can produce geologically valuable information, such as relative ages of flow surfaces [Evans et al., 1981], they may hinder understanding of the "true" substrate lithology.

[4] Secondary silica has been predicted to be mobile on the surface of Mars, a result of alteration of olivine, pyroxene and volcanic glass [McLennan, 2003]. Recently, those predictions have been confirmed by in situ observations; in particular, high-silica materials $\left(>90 \% \mathrm{SiO}_{2}\right)$ thought to be the products of hydrothermal alteration have been discovered by the Spirit rover at Home Plate [Arvidson et al., 2008; Squyres et al., 2007, 2008]. Orbital spectra of the Martian 
surface have also suggested the presence of secondary silica. The presence of hydrated silica-rich material, as indicated by $\mathrm{Si}-\mathrm{OH}$ vibrational bands at $2.21-2.25 \mu \mathrm{m}$ in CRISM spectra, has been confirmed in bedded units near Valles Marineris [Milliken et al., 2008] and in highland craters at Nili Fossae [Mustard et al., 2008; Ehlmann et al., 2009]. Thermal Emission Spectrometer (TES) data have been used to identify two compositionally distinct surface types [Bandfield et al., 2000]. Surface Type 2 (ST2) was initially modeled as an andesitic composition, but is also consistent with phyllosilicatebearing weathered basalt [Wyatt and McSween, 2002], palagonitized basalt [Morris et al., 2003], or opaline silica-coated basalt [Kraft et al., 2003]. The wide spatial domain of ST2 indicates that silica coatings may be common on the Martian surface. These detections of silica imply a wet, thermally active and potentially habitable environment on the Martian surface, at least in localized areas. Additionally, silica deposits may also be among the most favorable lithologies for preserving microbial fossils on Mars [Farmer and Des Marais, 1999]. Understanding the nature of these coatings can provide vital information on past climatic and atmospheric conditions, as well as geologic context.

[5] Without sample return of high-silica materials from Mars, we rely on analog materials to better understand Martian geochemical processes. Hawaii has long been considered a viable physical and chemical analog to Mars [e.g., Bell et al., 1993]. Specifically, the Ka'u Desert, on the southwestern flank of Kilauea, is a robust analog because of its young surface age and acid-sulfate-driven alteration processes [Seelos et al., 2010] (Figure 1). In addition, Airborne Visible/Near Infrared Imaging Spectrometer (AVIRIS) has collected hyperspectral reflectance data sets of the Ka'u Desert at the same spatial resolution as CRISM, allowing for direct comparison of data set analyses. Hawaiian silica coatings, therefore, are ideal subjects of study to understand the processes that may have occurred on Mars to produce secondary silica deposits. Previous researchers have analyzed a variety of silica coatings from all five volcanoes on the Big Island [e.g., Minitti et al., 2007; Farr and Adams, 1984; Curtiss et al., 1985]. We focus on a single suite of samples from the Ka'u Desert, employing a variety of techniques for in-depth characterization of the coatings at multiple scales. These include chemical analysis, high-resolution imagery, Raman and transmission IR spectroscopic analysis, and the first (to our knowledge) oxygen isotopic measurements of Hawaiian basalt coatings. The goal of this study is to characterize these coatings, determine their formation mechanism, and describe the implications for silica mobility in the Hawaiian and Martian systems.

\section{Materials and Methods}

[6] This study focuses primarily on a suite of coated basalt samples from the Kilauea December 1974 pahoehoe flow, collected in the Ka'u Desert in 2002 and 2003 (Figure 1). This flow originated from several fissure vents near the Southwest Rift and displays heterogeneous surface morphology [Soule et al., 2004]. Rock samples were collected at two sites on the 1974 flow: (1) near the fissure vents closest to Kilauea Caldera, on heavily coated spatter ramparts, and (2) close to the distal end of the flow, where the pahoehoe transitions into a'a. Additional description of Ka'u Desert collection locales can be found in the work of Seelos et al. [2010]. Additional analyses were performed on coated samples from the Mauna Ulu 1974 flow, collected just north of the Chain of Craters Road. Samples were stored at room temperature after their collection; humidity was not controlled.

[7] Samples were analyzed by Raman spectroscopy, using a HoloLab 5000 Raman system with a $632.8 \mathrm{~nm}$ He-Ne laser at Washington University, and using a Renishaw M1000 micro Raman spectrometer with a $514.5 \mathrm{~nm}$ argon laser at Caltech. The spot size used was typically $\sim 1 \mu \mathrm{m}$. Mineral identifications based on Raman spectra were performed using the Washington University Raman database and the UA-Caltech RRUFF database.

[8] In order to determine water content and speciation within the coatings, transmission IR spectra were acquired with a Nicolet Magna-IR spectrometer at Caltech, using a liquid $\mathrm{N}_{2}$ cooled mercury cadmium telluride (MCT-A) detector and a $\mathrm{KBr}$ beam splitter. Spectra were collected in the $2000-4000 \mathrm{~cm}^{-1}$ range. Wafers of coated and uncoated basalts were prepared by polishing to a thickness of 50 $100 \mu \mathrm{m}$. Transmission spectra were acquired through the wafers, perpendicular to the basalt-coating interface.

[9] Major and minor element compositional data was acquired by electron probe microanalysis (EPMA) using a JEOL 733 Superprobe with Advanced Microbeam Inc. automation, at Washington University. Quantitative data were acquired using wavelength dispersive spectrometry, operating at $15 \mathrm{kV}$ accelerating voltage and beam currents of either $20 \mathrm{nA}$ or $30 \mathrm{nA}$. Nominal spot sizes ranged from 1 to $10 \mu \mathrm{m}$ in diameter; the smallest analytical volumes were likely around 3-4 $\mu \mathrm{m}$ across. Glasses of varying composition, including Hawaiian basalt and fused silica glass, were used for standardization. Both cross-sectional thick sections and natural flat surfaces of coated basalts were analyzed. The use of natural surfaces with irregular geometries led to occasional charging effects and low totals, but preserved the integrity of the thin, friable coatings. Additional chemical imaging was conducted by NanoSIMS at Caltech, using a duoplasmatron $\left(\mathrm{O}_{2}^{-}\right)$primary beam for mapping the distribution of metals and transition metals and $\mathrm{a} \mathrm{Cs}^{+}$primary beam for mapping nonmetals. Backscattered electron (BSE) images were obtained both by electron microprobe and with a LEO 1550 VP field emission scanning electron microscope (SEM) at Caltech. Secondary electron (SE) images were also obtained by SEM at a range of magnifications (250-50,000×). An Oxford Inca X-ray energy dispersive spectrometer (EDS) was used for concurrent elemental analyses.

[10] Oxygen isotopic analyses were conducted on a Cameca $7 \mathrm{f}$ ion microprobe and by NanoSIMS at Caltech. A chip of the Hawaiian coating was polished at a small angle relative to the surface to expose large regions of the coating for analysis and to minimize topography on the sample surface. Analyzed standards included HSQ glass (pure $\mathrm{SiO}_{2}$ ), described by Eiler et al. [1997], and laboratory silica glass. In addition, two Ti-oxide samples, a synthetic rutile from Russia and an ilmenite ore sample from Baie St. Paul, Quebec, Canada, were mounted as standards. Samples and standards were coated with $50 \mathrm{~nm}$ Au before analysis. Cameca $7 \mathrm{f}$ measurements were made with a $\mathrm{Cs}^{+}$primary beam, focused to a $\sim 40 \mu \mathrm{m}$ spot. Secondary ${ }^{16} \mathrm{O}^{-}$and ${ }^{18} \mathrm{O}^{-}$ 


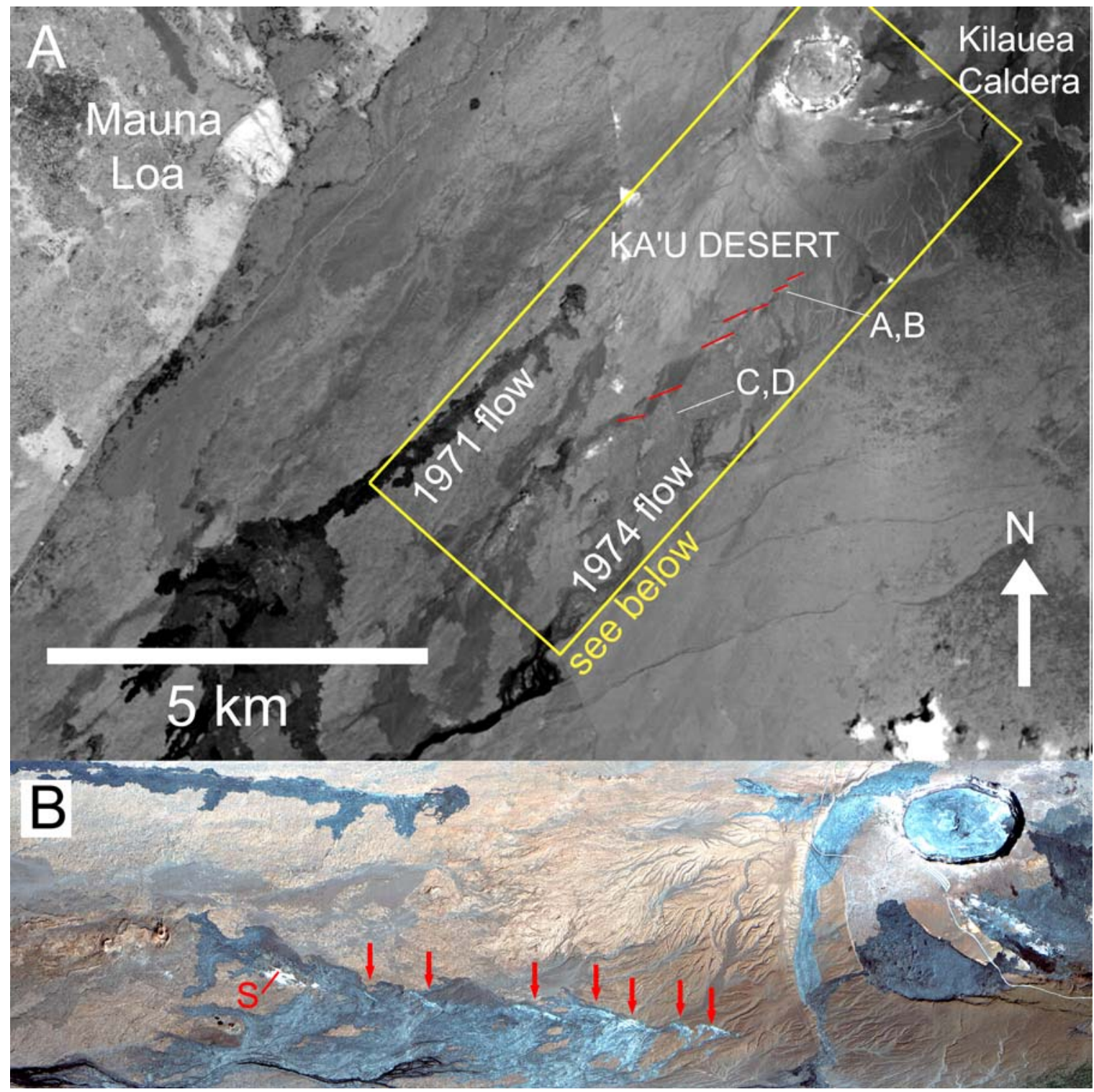

Figure 1. (a) Google Earth imagery of the Ka'u Desert. Locations A-D indicate photos and hand samples shown in Figures 2a-2d; red lines indicate approximate locations of 1974 flow fissure vents. (b) AVIRIS false color composite image of 1974 flow, using 1.24, 0.66, and $0.48 \mu \mathrm{m}$ as RGB, respectively. Red arrows indicate 1974 fissure vents. "S" indicates an active solfatara, not discussed further in this paper (adapted from Seelos et al. [2010]) Google Earth imagery CGoogle Inc. Used with permission.

ions were pseudosimultaneously measured by magnetic peak switching and with two Faraday cups. Typical count rates were around $2 \times 10^{9} \mathrm{cps}$ for ${ }^{16} \mathrm{O}$ and $4 \times 10^{6} \mathrm{cps}$ for ${ }^{18} \mathrm{O}$. NanoSIMS measurements were made with a $\mathrm{Cs}^{+}$primary beam and a $6 \mu \mathrm{m}$ raster size. Typical ${ }^{16} \mathrm{O}$ count rates were around $5 \times 10^{8} \mathrm{cps}$. The oxygen isotope compositions of the silica glass and Ti-oxide standards, as well as the bulk basaltic glass of the sample, were determined by conventional laser fluorination techniques [Valley et al., 1995].

\section{Results}

\subsection{Coating Morphology}

[11] The 1974 Kilauea flow prominently features discontinuous opaque coatings, colored white, pale yellow, pale blue or pale orange, on many subaerial surfaces within several hundred meters of the source vents. These pale surfaces correspond to the Fe- and Ti-rich coating layer, as described below. The Fe-Ti coatings cover high areal proportions of the surfaces of spatter ramparts lining the fissure vents (Figures $2 \mathrm{a}$ and $2 \mathrm{~b}$ ); the areal proportion of coverage drops with distance from the vents (Figures $2 c$ and $2 d$ ). The gradient in pale coating coverage away from the fissures is manifested in remote visible/near infrared (VNIR) images as a gradient in brightness (Figure 1b). On samples where areal coverage is less than full, the pale coating appears to form primarily in topographic lows. Nearly all subaerial surfaces also feature a colorless coating layer of near-pure $\mathrm{SiO}_{2}$ that underlies the pale, visually prominent Fe-Ti coating. These silica coatings are difficult to identify by sight in the field, 


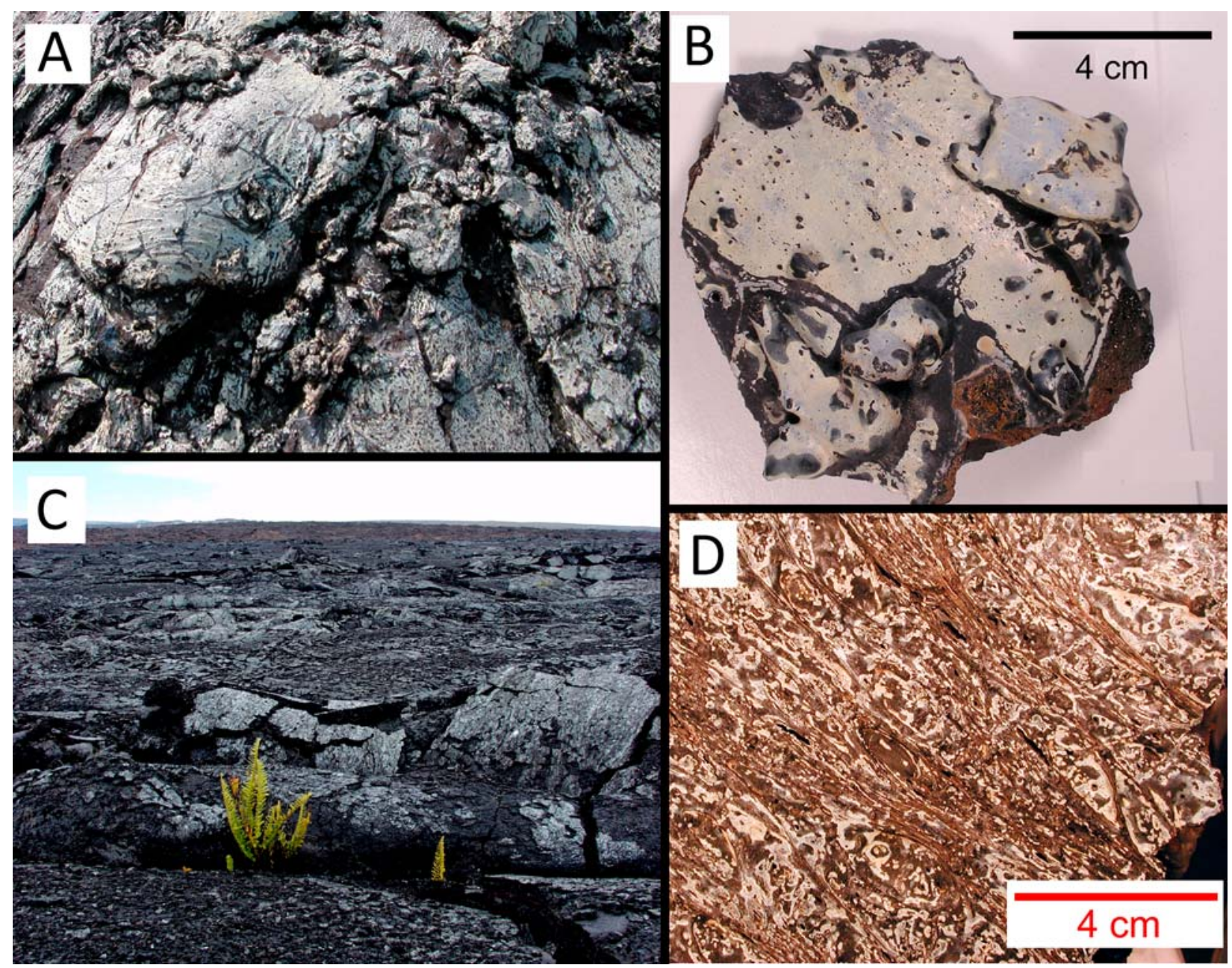

Figure 2. Macroscopic coating morphology. (a) Coated spatter "pancakes" on the 1974 Kilauea flow. Field of view is $\sim 2 \mathrm{~m}$ across. (b) Hand sample of coated spatter rampart. Bright surface areas feature the Fe-Ti coating. (c) Distal end of 1974 flow. Note that surfaces exposed by spallation appear fresh and uncoated. (d) Coated sample collected on distal end of 1974 flow, on which the Fe-Ti coatings are sparser.

but are identifiable by absorption features associated with Si-OH and $\mathrm{H}_{2} \mathrm{O}$ fundamental and overtone vibrations in field and remote reflectance spectra [Seelos et al., 2010]. In places where the glassy flow surface has cracked or spalled away by physical weathering, the exposed basalt surfaces appear fresh and uncoated (Figure 2c). Some leeward edges of the 1974 flow have no apparent coating, the result of abrasion by windblown ash deposits [Seelos et al., 2010] (Figure 1b).

[12] SEM and BSE images of polished cross sections of coated basalt samples indicate two prominent coating layers. A layer of amorphous silica directly overlies the basaltic glass substrate (Figures 3a-3d). A second, thinner $(<1.5 \mu \mathrm{m})$ layer, not always present, appears bright in BSE images and is composed primarily of Fe-Ti oxides. The glass substrate appears physically unaltered up to the coating boundary. The silica-basalt boundary is sharp but undulating and appears to be made up of crisscrossing fractures dissecting the glass surface. This veined texture continues through the entire silica layer, and veins apparently contribute to increased porosity at the outer edges of the layer. The thickness of the silica coating of samples analyzed for this study was fairly constant around $\sim 10 \mu \mathrm{m}$; other researchers have reported more variable thicknesses of 5-70 $\mu \mathrm{m}$ [Minitti et al., 2007]. Although we did not collect samples with sufficient spatial resolution to characterize coating thickness gradients away from the vents in detail, analyses of samples from our two collection sites suggest that silica coating thickness is uncorrelated to the areal coverage of the Fe-Ti coating. In addition to the surface coatings, some interior vesicles, hundreds of microns below the surface and surrounded by otherwise unaltered basaltic glass, are lined with high-silica material (Figure 3g).

[13] SEM images of the coating surface and of natural broken surfaces were also collected. The coating surface is an aggregate of spherules $50-150 \mathrm{~nm}$ in diameter (Figures $3 \mathrm{e}-$ 3f). In places, these spherules congeal together into larger globules up to $1 \mu \mathrm{m}$ across. EDS analysis of the spherules indicate high $\mathrm{Fe}$ and $\mathrm{Ti}$ content. On some coating surfaces, Ti-rich and Si-rich materials form alternating bands or lamellae. Fractures, possibly formed by shrinkage during cooling or by dessication, dissect the surface into polygo- 


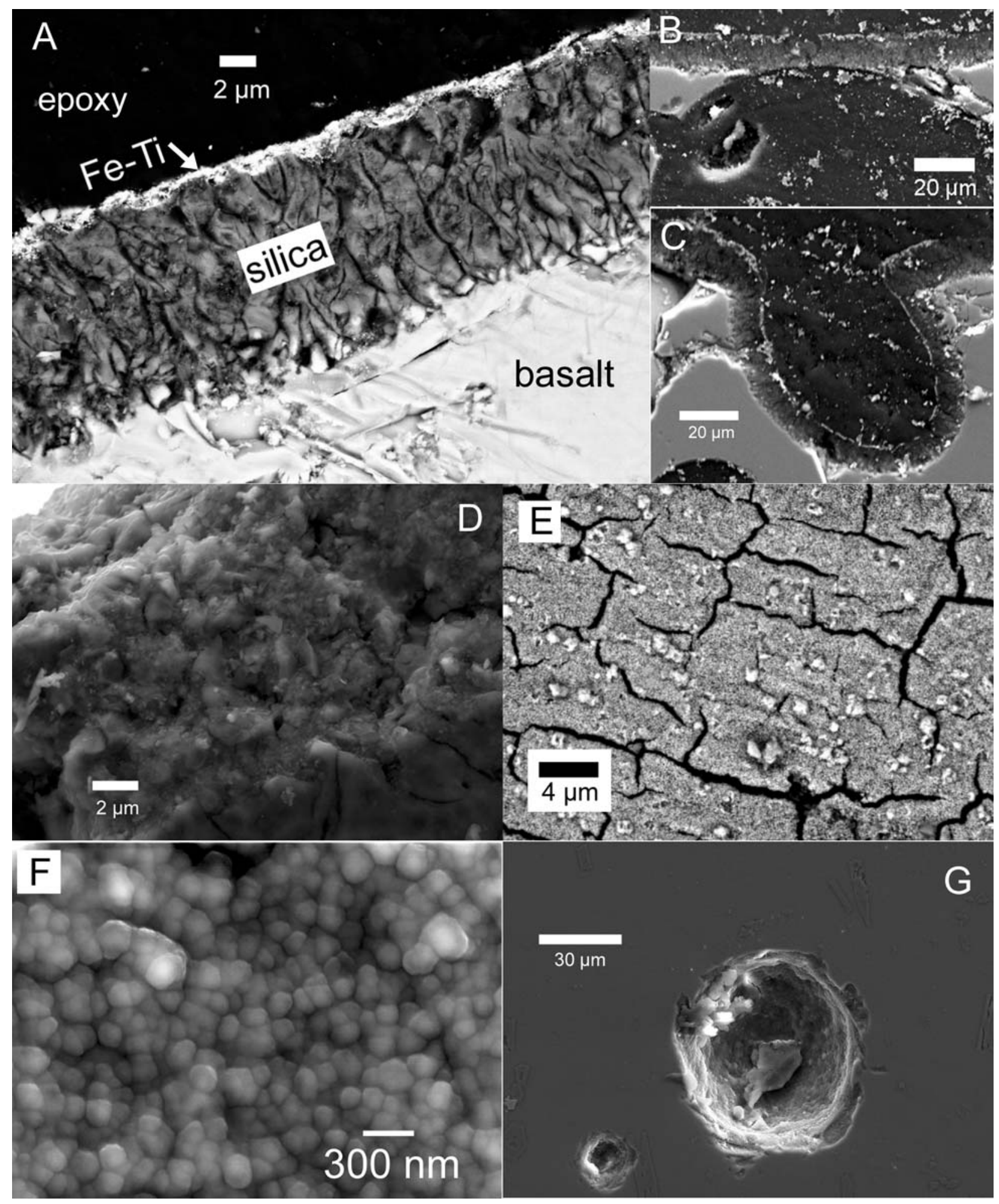

Figure 3. SEM and BSE imagery of coating morphologies. (a) Backscatter electron image of typical coating morphology; unaltered basalt substrate, with a $\sim 10 \mu \mathrm{m}$ silica coating on top, capped by a $\sim 1 \mu \mathrm{m} \mathrm{Fe}-\mathrm{Ti}$ oxide coating. (b) In places, the coating overlies near-surface vesicles, implying a residual rather than depositional formation. (c) Near-surface vesicle featuring coating on all sides, again implying a residual formation mechanism. (d) SE image of porous, irregular silica material. (e) BSE image of natural coating surface, illustrating granular, sometimes ridged surface appearance with desiccation cracks. (f) Spheroidal aggregate morphology of Fe-Ti coating on surface. (g) An interior vesicle with thin $(\sim 1 \mu \mathrm{m})$ silica coating, as identified by EDS. 


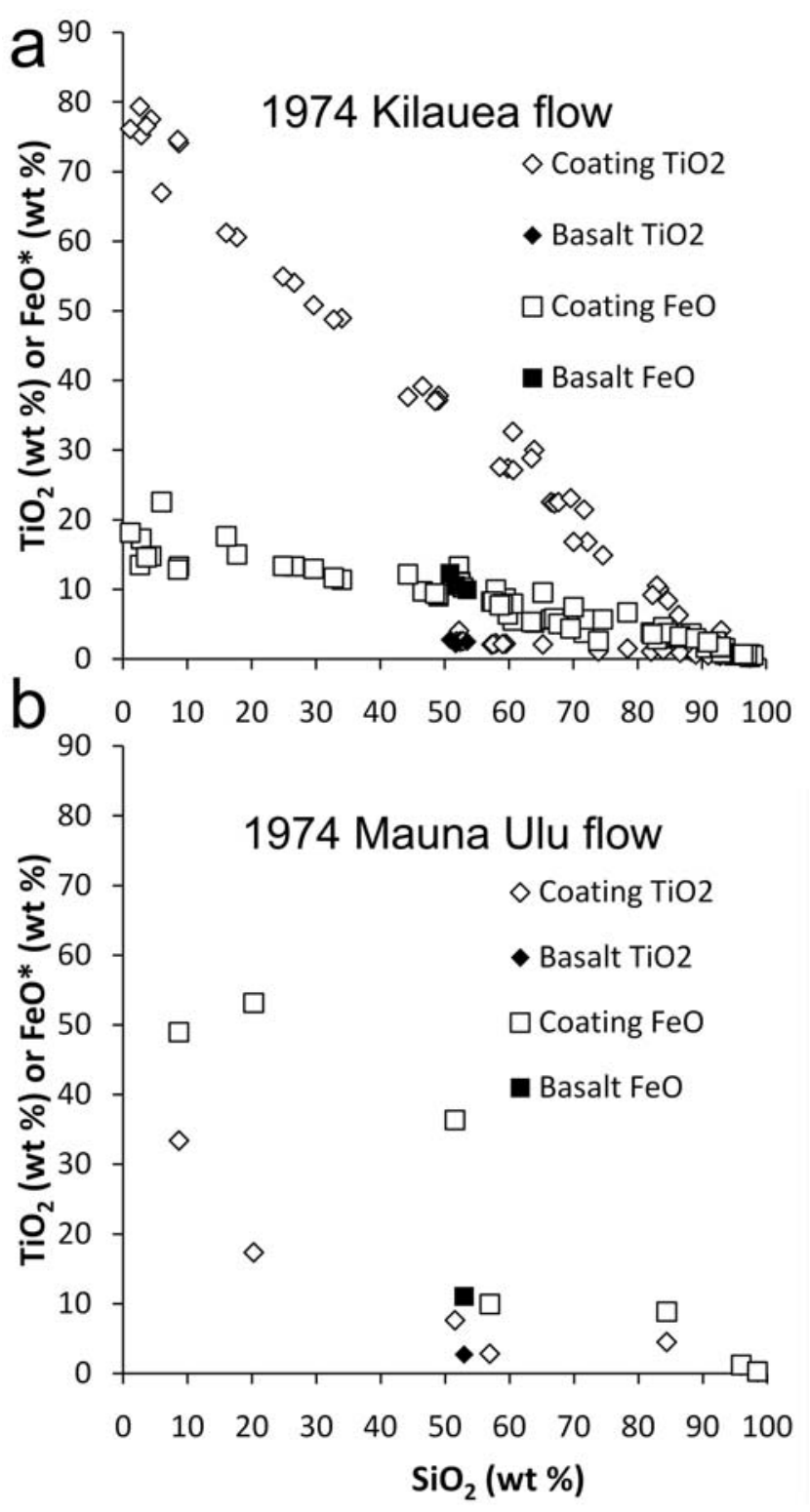

Figure 4. Compositional analyses. $\mathrm{TiO}_{2}$ and $\mathrm{FeO}^{*}$ concentrations are displayed as diamonds and squares, respectively. Basalt substrate analyses are represented by filled symbols; coating analyses are open symbols. (a) 1974 Kilauea flow analyses. The observed trends can be explained by two mixing trends between basalt and silica coating end-members and between silica coating and $\mathrm{Fe}-\mathrm{Ti}$ oxide end-members. (b) 1974 Mauna Ulu flow analyses. The Fe/Ti ratio of the Fe-Ti oxide end-member is lower and more variable than that of the Kilauea coatings.

nal platelets $\sim 10 \mu \mathrm{m}$ across (Figure 3e). Flecks of uncoated basaltic glass overlie the coating surface, likely ash particles postdating the coating formation. Examination of broken surfaces of the coating indicates that the lower coating layer does not share the same spheroidal aggregate morphology. Instead, the lower layer is angular, irregular and porous (Figure 3d). The textural boundary likely corresponds to the compositional boundary between $\mathrm{SiO}_{2}$-rich and $\mathrm{Fe}$-Ti-rich material.
[14] Spheroidal aggregrate morphology is commonly associated with opaline silica, but has also been observed in deposited films of anatase [Shimizu et al., 1999; Sankapal et al., 2005] and amorphous titania [Oguri et al., 1988]. In opals, spheroidal aggregate morphology is observed to form in a variety of environments, including precipitates in groundwater systems, vapor deposition, and fabricated thin films [Gu et al., 2002]. Although spheroidal aggregates can occur in residual environments [Rodgers et al., 2002], the texture is generally associated with depositional processes. Based on the variations in composition of the coating surface as indicated by EDS, we interpret the spheres as deposited amorphous $\mathrm{Fe}-\mathrm{Ti}$ oxides. The variations in sphere size may relate to variations in water-to-rock ratio and other conditions of deposition.

\subsection{Coating Chemistry}

[15] Electron microprobe analyses of the Ka'u Desert coatings indicate three compositional end-members: unaltered basaltic glass, and two coating compositions (Table 1). The basaltic substrate is an olivine-normative tholeiite. The basaltic glass is unchanged in composition even $<2 \mu \mathrm{m}$ from the edge of the silica coating, indicating the absence of a leaching profile at the spatial resolution of the electron microprobe. The compositions of spot analyses on the coatings are linear mixtures of two end-members (Figure 4a). The opaline layer is typically $93-100 \mathrm{wt} \% \mathrm{SiO}_{2}$, with minor concentrations of $\mathrm{Al}_{2} \mathrm{O}_{3}, \mathrm{MgO}, \mathrm{FeO}^{*}$, and $\mathrm{CaO}$ and enrichments in $\mathrm{SO}_{3}$. Because the outer opaque coating layer is so thin, it was difficult to isolate it in a single beam diameter during EPMA. An ideal, $\mathrm{SiO}_{2}$-free end-member composition was calculated as $\sim 75 \% \mathrm{TiO}_{2}$ and $\sim 20 \% \mathrm{FeO}^{*}$, with percentlevel enrichments in $\mathrm{SO}_{3}$ and $\mathrm{P}_{2} \mathrm{O}_{5}$. This Ti/Fe ratio does not correspond to the stoichiometry of any single $\mathrm{Fe}$-Ti oxide phase; it lies between pure $\mathrm{TiO}_{2}$ and the pseudobrookiteferropseudobrookite join. Many spot analyses of coating surfaces suffer from low totals, likely the result of nonideal topography, porosity, and significant water content of the coating (as verified by transmission IR spectroscopy below).

[16] EPMA traverses across the coatings reveal concentration gradients in basaltic cations $\left(\mathrm{Al}^{3+}, \mathrm{Mg}^{2+}, \mathrm{Ca}^{2+}, \mathrm{Na}^{+}\right)$ away from the basalt-coating interface (Figure 5). All of these elements display similar depletion factors across the coating, leading to parallel trends on a log-scale plot of concentration. Both the opaline layer and the outer layer are enriched in S; the sulfur content of the coating increases continuously with distance from the basalt substrate, and does not vary much across the silica- $\mathrm{TiO}_{2}$ boundary (Figure 5).

[17] To test regional homogeneity of Ka'u Desert coatings, samples collected from the Mauna Ulu 1974 flow, roughly $10 \mathrm{~km}$ east, were also analyzed. Although the morphology of the Mauna Ulu coatings is similar to that of the Ka'u Desert coatings, their chemistry is distinct. Compositional analyses of Mauna Ulu coatings cannot be explained by mixing of two end-members, indicating heterogeneity in the $\mathrm{Ti} / \mathrm{Fe}$ ratio in the outer coating layer (Figure $4 \mathrm{~b}$ ). The $\mathrm{Ti} / \mathrm{Fe}$ ratio of the outer layer is significantly lower than that of the Ka'u Desert coatings; the most Si-poor analysis featured $\sim 35 \% \mathrm{TiO}_{2}$ and $\sim 50 \% \mathrm{FeO}^{*}$. This ratio implies a different mineralogy, potentially a mixture of anatase and hematite.

[18] Spatial variations in coating composition were explored by NanoSIMS mapping. Spatial resolution of images 
Table 1. Representative Electron Microprobe Measurements of Coatings on 1974 Kilauea Flow ${ }^{\text {a }}$

\begin{tabular}{|c|c|c|c|c|c|}
\hline & \multirow[b]{2}{*}{ Basalt } & \multirow[b]{2}{*}{ Silica Coating } & \multirow[b]{2}{*}{ Fe-Ti Coating } & \multicolumn{2}{|c|}{ Representative Normalized End-Members } \\
\hline & & & & Silica Coating & Fe-Ti Coating \\
\hline $\mathrm{SiO} 2$ & 51.87 & 94.87 & 0.88 & 97.36 & 0 \\
\hline $\mathrm{TiO} 2$ & 2.48 & 0.19 & 59.44 & 0.19 & 77.05 \\
\hline $\mathrm{Al} 2 \mathrm{O} 3$ & 13.3 & 0.12 & 0.02 & 0.12 & 0.02 \\
\hline $\mathrm{FeO}^{*}$ & 10.59 & 0.28 & 14.16 & 0.29 & 18.35 \\
\hline $\mathrm{MnO}$ & 0.17 & 0.06 & 0 & 0.06 & 0 \\
\hline $\mathrm{MgO}$ & 7.44 & 0.33 & 0.02 & 0.34 & 0.02 \\
\hline $\mathrm{CaO}$ & 11.02 & 0.06 & 0.22 & 0.06 & 0.28 \\
\hline $\mathrm{Na} 2 \mathrm{O}$ & 2.71 & 0.03 & 0.05 & 0.03 & 0.06 \\
\hline $\mathrm{K} 2 \mathrm{O}$ & 0.47 & 0.03 & 0.02 & 0.03 & 0.02 \\
\hline P2O5 & 0.25 & 0.02 & 2.04 & 0.02 & 2.64 \\
\hline $\mathrm{Cr} 2 \mathrm{O} 3$ & 0.06 & 0.04 & 0.03 & 0.04 & 0.04 \\
\hline $\mathrm{SO} 3$ & 0.045 & 1.41 & 1.19 & 1.45 & 1.53 \\
\hline Total & 100.405 & 97.44 & 78.07 & 100.00 & 100.00 \\
\hline
\end{tabular}

${ }^{\mathrm{a}}$ End-member compositions are normalized to $100 \%$; Fe-Ti normalized end-member calculated assuming zero $\mathrm{SiO}_{2}$.

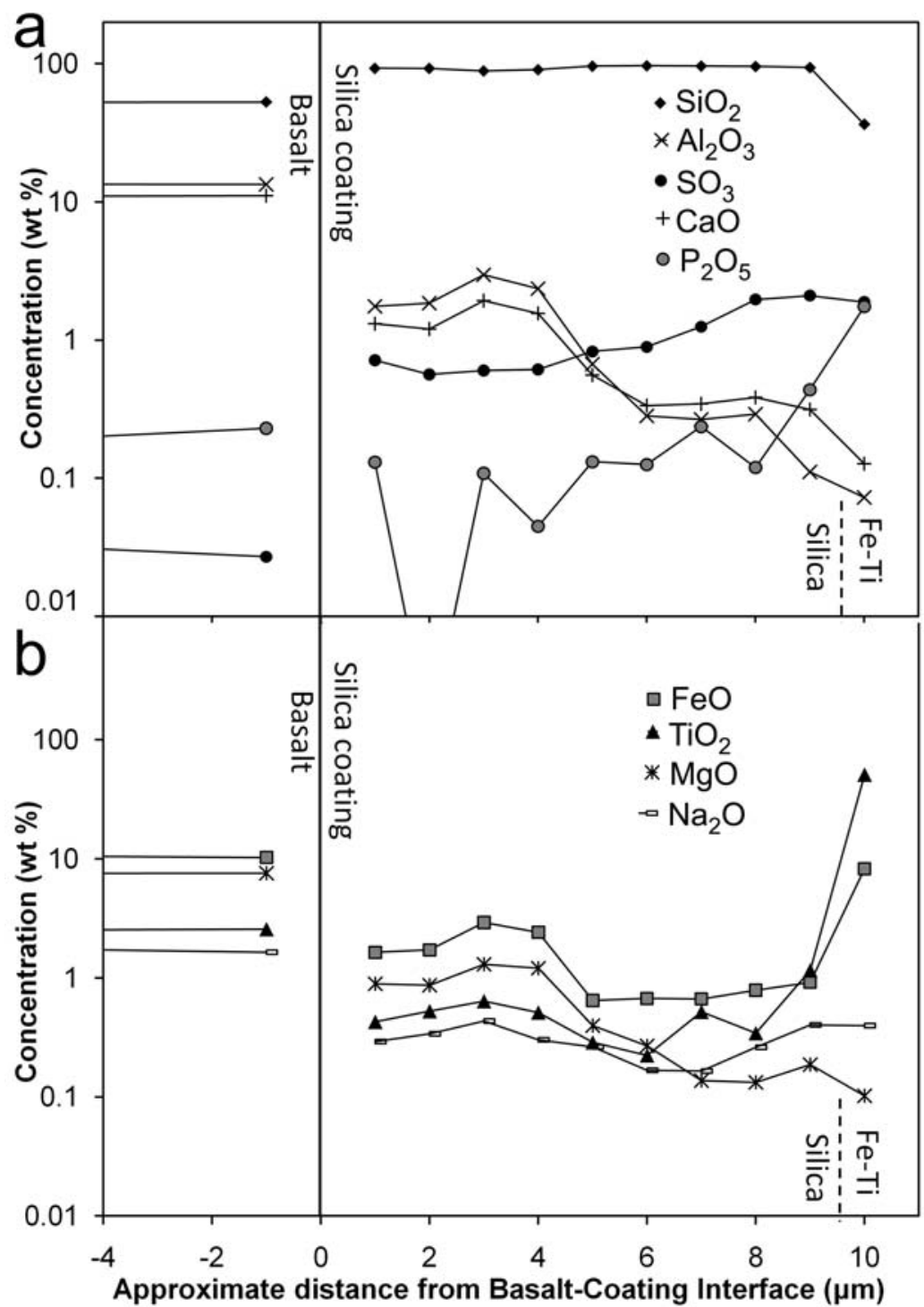

Figure 5. Microprobe traverse across a cross section of Kilauea 1974 coating for (a) $\mathrm{SiO}_{2}, \mathrm{Al}_{2} \mathrm{O}_{3}, \mathrm{SO}_{3}$, $\mathrm{CaO}$, and $\mathrm{P}_{2} \mathrm{O}_{5}$, and (b) $\mathrm{FeO}, \mathrm{TiO}_{2}, \mathrm{MgO}$, and $\mathrm{Na}_{2} \mathrm{O}$. All analyses are normalized to $100 \%$. Basaltic elements are depleted in the silica coating; depletion factors for each element are similar. $\mathrm{S}$ concentration varies smoothly through coating and increases toward Fe-Ti-rich edge. 

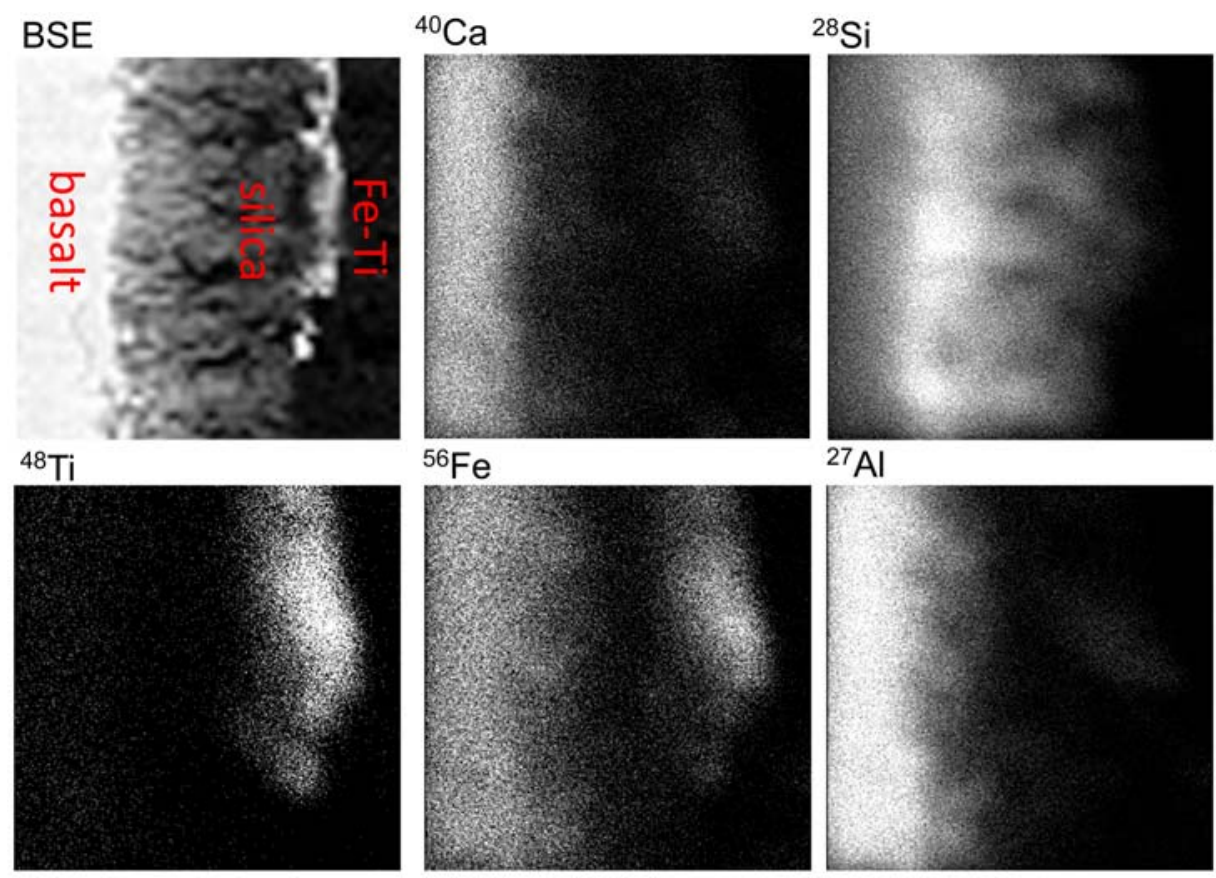

Figure 6. NanoSIMS elemental maps collected with $\mathrm{O}_{2}^{-}$, with BSE image for comparison. Each map is $20 \times 20 \mu \mathrm{m}$. Spatial resolution is $\sim 1.5 \mu \mathrm{m}$.

acquired with the $\mathrm{O}_{2}^{-}$source was determined to be $\sim 1.5 \mu \mathrm{m}$ (Figure 6). The Si map confirms that the lower coating layer is enriched in $\mathrm{Si}$. The intensity of the $\mathrm{Si}$ counts decreases with distance from the substrate, suggesting an increase in void or pore space away from the edge. Maps of $\mathrm{Ca}, \mathrm{Al}$, and $\mathrm{Mg}$ (not pictured), elements associated with the basaltic substrate, indicate that these elements are depleted in the coating materials. Concentration gradients in these elements are apparent near the basalt substrate edge, corroborating EPMA traverse results (Figure 5); in the outer half of the silica coating layer, these basaltic elements are nearly absent. The outer coating layer is strongly enriched in Ti and Fe. The interface between the two coating layers is not sharp, but this may be an analytical artifact.

[19] The distribution of various nonmetals in the coating was determined by NanoSIMS mapping using the $\mathrm{Cs}^{+}$ source; spatial resolution of these images was $\sim 500 \mathrm{~nm}$ (Figure 7). Each element was ratioed to ${ }^{16} \mathrm{O}$ because oxygen concentration is roughly constant across silicates. Variations in ${ }^{16} \mathrm{O}$ intensity (not pictured) were the result of void space in the material and matrix effects. The $\mathrm{Cs}^{+}$maps indicate strong $\mathrm{F}$ enrichment in the outer, Ti-rich coating. This enrichment suggests that the deposition of the Ti-rich coating occurred in a halide-rich environment and may have involved Ti-halide complexes [Barsukova et al., 1979]. Chlorine is largely absent from the outer layer; this absence could be the result of postdepositional dissolution and removal, as most chlorides are soluble. The outer coating also features enrichments in phosphorus, which commonly has limited mobility in weathering environments. Sulfur occurs only at low concentrations in the Fe-Ti coating and is instead concentrated heterogeneously within the silica layer. The relative absence of $\mathrm{S}$ in the outer coating suggests that $\mathrm{S}$ remained soluble in the solutions from which the $\mathrm{Fe}-\mathrm{Ti}$ oxide was chemically precipitated. Sulfur hot spots may represent locations where jarosite (as identified by Raman, discussed below) is present.

\subsection{Spectral Properties and Mineralogy}

\subsubsection{Reflectance Spectroscopy}

[20] The results of field and laboratory reflectance spectra in the visible and near-IR regions $(0.4-2.5 \mu \mathrm{m})$ of coating samples from the Ka'u Desert are described in detail elsewhere [Seelos et al., 2010]. Absorption features in these spectra include an absorption edge centered at $0.4 \mu \mathrm{m}$ and a broad band at $1.0 \mu \mathrm{m}$, both the result of ferric iron in the sample. Molecular water is indicated by absorptions at 1.4 and $1.9 \mu \mathrm{m}$, and structural $\mathrm{OH}$ in opaline silica $(\mathrm{Si}-\mathrm{OH}$ vibration) is indicated by a band at $2.23 \mu \mathrm{m}$ (Figure 8). Thinner coating samples displayed a negative slope in reflectance toward longer wavelengths, but thick coating samples did not display this feature. This negative slope is possibly the result of absorption by the basaltic substrate underneath an optically thin coating. The spectral features described above, particularly the ferric iron absorption edge and the $2.23 \mu \mathrm{m}$ silica absorption, are also observed in remote AVIRIS spectra of the 1974 flow [Seelos et al., 2010].

\subsubsection{Raman Spectroscopy}

[21] Because the Fe-Ti coating is optically opaque at the wavelength of our Raman laser, Raman spectral analyses of the coating surface are dominated by the mineralogy of the Fe-Ti phase. Signatures of the opaline silica coating and of the unaltered basalt are masked by the strong absorptions of the titanium oxides. At least three different phases were identified in the Fe-Ti-rich layer (Figure 9). One spectrum is indicative of anatase, although peak positions are commonly shifted from those previously documented and calculated for pure crystalline anatase [Ohsaka et al., 1978]. The intense 


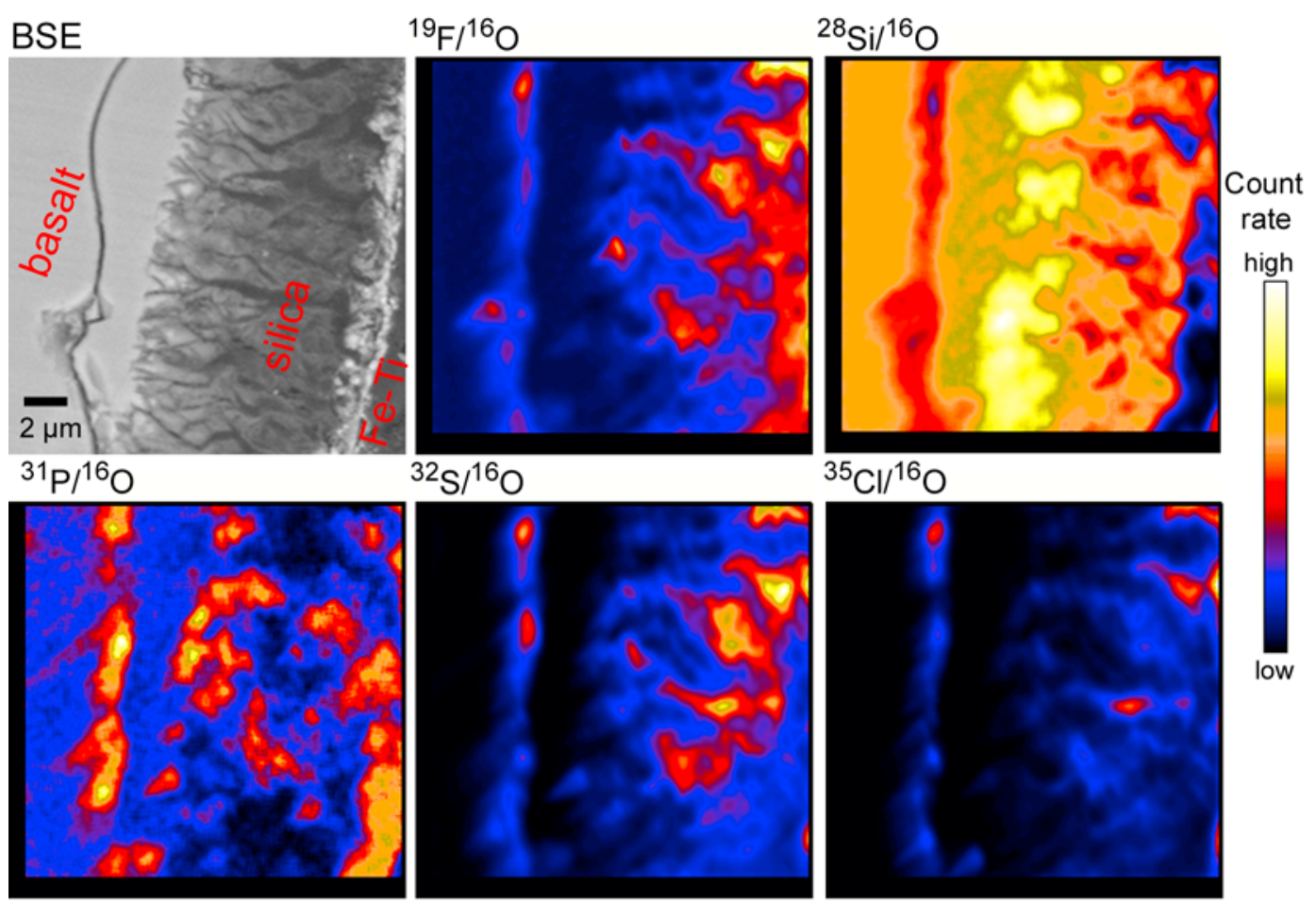

Figure 7. NanoSIMS elemental ratio maps collected with $\mathrm{Cs}^{+}$beam, with BSE image for comparison. Each element is ratioed to ${ }^{16} \mathrm{O}$ because oxygen concentration is roughly constant across the coating gradient. The linear feature present on the right side of each map is a crack in the basalt substrate. Each map is $20 \times 20 \mu \mathrm{m}$; spatial resolution is $\sim 500 \mathrm{~nm}$.

band corresponding to the $\nu_{6}$ vibrational mode, normally found at $144 \mathrm{~cm}^{-1}$, is present but is cut off due to low instrument sensitivity below $150 \mathrm{~cm}^{-1}$. Peaks at $397 \mathrm{~cm}^{-1}$, $508 \mathrm{~cm}^{-1}$, and $638 \mathrm{~cm}^{-1}$ correspond to the $\nu_{4}, \nu_{3}$, and $\nu_{1}$ vibrational modes, respectively. The FWHMs of these peaks are larger than those of published spectra of crystalline an-

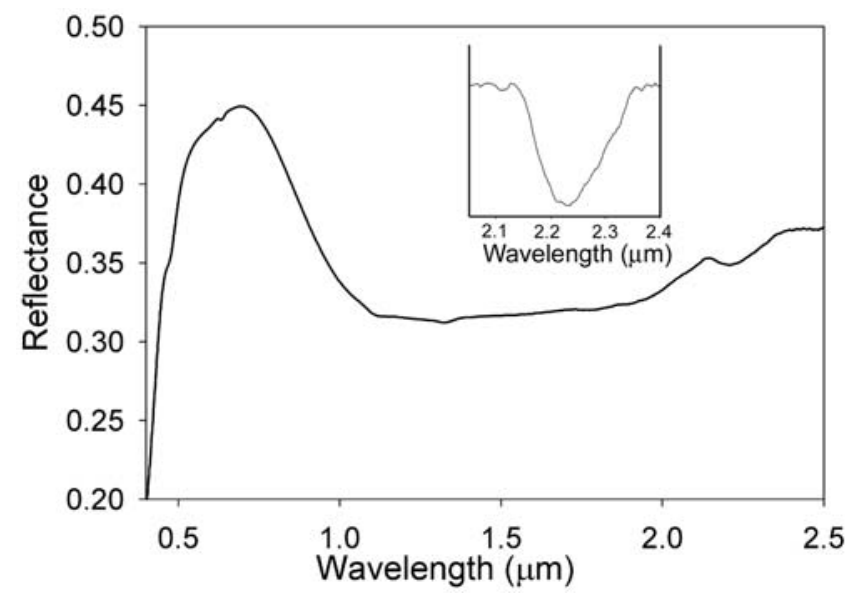

Figure 8. Reflectance spectrum of coated Kilauea basalt. Prominent spectral features include an $\mathrm{Fe}^{3+}$ absorption edge and an $\mathrm{Si}-\mathrm{OH}$ vibrational feature at $2.23 \mu \mathrm{m}$ indicating opaline silica. The inset shows the $\mathrm{Si}-\mathrm{OH}$ feature with baseline removed. (Adapted from Seelos et al. [2010].)

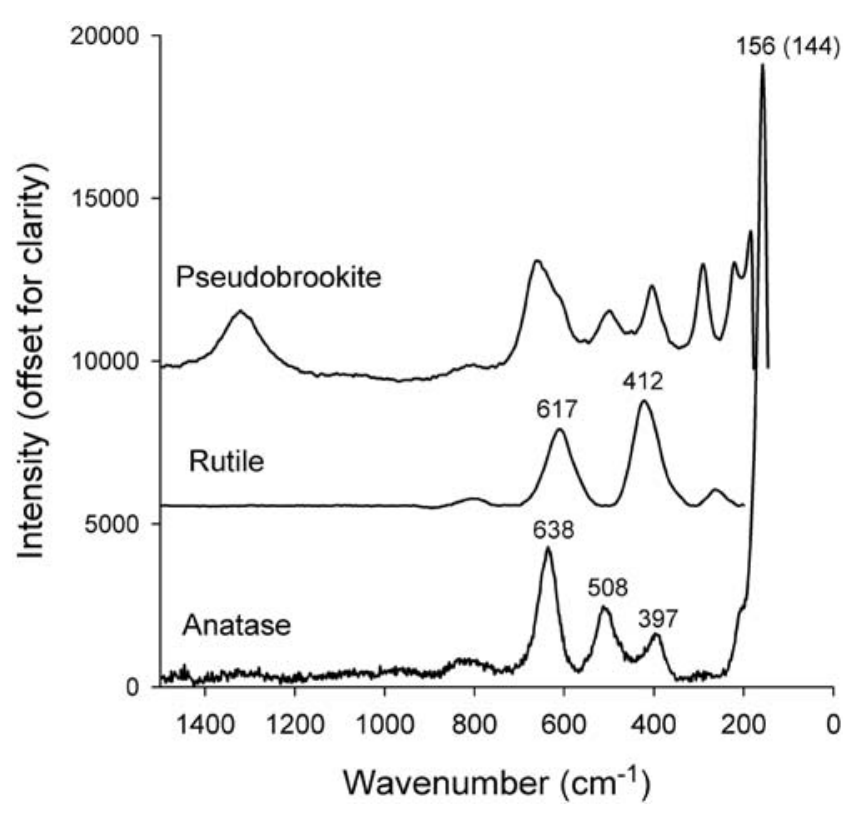

Figure 9. Selection of Raman spectra of Fe-Ti-rich coating. Definitive identifications include anatase and rutile; however, peak shifts in the spectra of both phases from previously published spectra may indicate varying degrees of crystallinity and $\mathrm{Fe}^{3+}$ substitution. Another spectrum is consistent with an Fe-Ti oxide in the pseudobrookite family. 


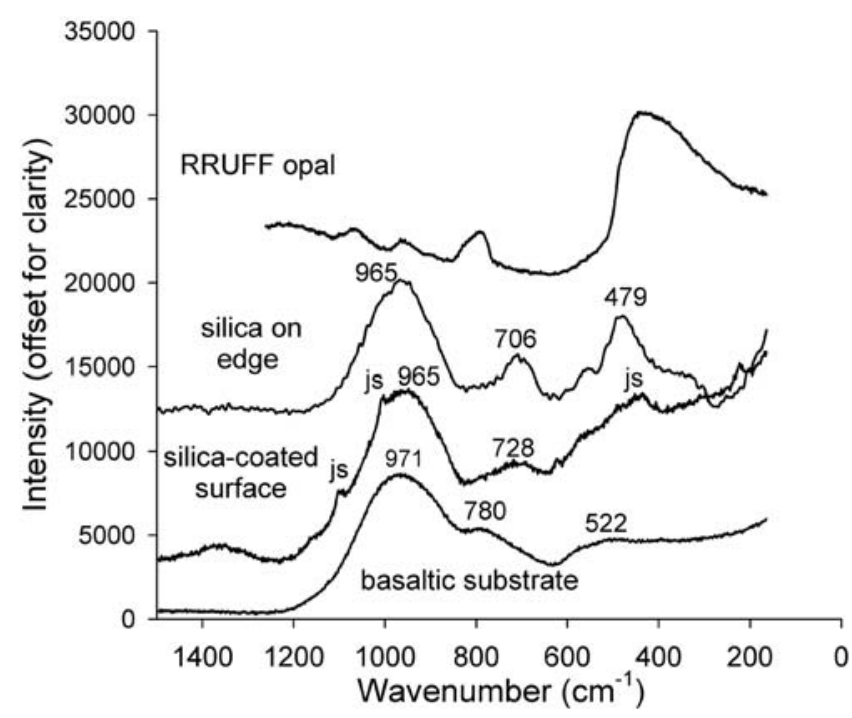

Figure 10. Selection of Raman spectra of amorphous silica coating, with an opal from the RRUFF library for comparison. Silica-rich materials are inconsistent with opal and are most consistent with leached basaltic glass. Jarosite (js) was also detected in analyses of silica-coated surfaces (see also Figure 11).

atase. The peak shifts and increased peak width can potentially be explained by variable degrees of crystallinity and by solid solution of $\mathrm{Fe}^{3+}$ in the anatase structure. Although most natural anatase samples previously analyzed include only 1-3 wt $\% \mathrm{Fe}_{2} \mathrm{O}_{3}$ [Liu and Mernagh, 1992], synthetic anatases have been precipitated containing up to $\mathrm{Fe} /(\mathrm{Ti}+\mathrm{Fe})$ $0.1 \mathrm{~mol} / \mathrm{mol}$ [Schwertmann et al., 1995]. Substitution of other metals for titanium in natural rutiles has been documented to shift Raman peak positions [Smith and Perseil, 1996]. Charge balance is likely accomplished by substitution of hydroxyl for oxygen, in the form $\mathrm{Fe}_{\mathrm{x}} \mathrm{Ti}_{(1-\mathrm{x})} \mathrm{O}_{(2-\mathrm{x})}(\mathrm{OH})_{\mathrm{x}}$ [Schwertmann et al., 1995]. Scraped coating shavings were analyzed by powder XRD to confirm the Raman mineral identification; weak, sharp peaks observed at $2 \theta=25.1^{\circ}$ and $47.5^{\circ}$ confirm the presence of crystalline, non X-rayamorphous anatase.

[22] Another frequently observed surface Raman spectrum also featured the intense $\nu_{6}$ band at $156 \mathrm{~cm}^{-1}$ associated with anatase, but had substantial peak shifts in the other $\mathrm{TiO}_{2}$ vibrational bands (Figure 9). The $\nu_{1}$ band normally found around $638 \mathrm{~cm}^{-1}$ is instead located at $617 \mathrm{~cm}^{-1}$, the $\nu_{4}$ band is located at $412 \mathrm{~cm}^{-1}$, and the $\nu_{3}$ band at $508 \mathrm{~cm}^{-1}$ is weak or nonexistent. This spectrum is consistent with a mixture of variably crystalline anatase and rutile; amorphous titania films may contain microcrystals of rutile even when deposited at low temperature [Hsu et al., 1986]. A third phase has no exact match in the RRUFF spectral library; its closest matches of the appropriate chemistry are members of the pseudobrookite group (i.e., $\mathrm{Fe}_{2} \mathrm{TiO}_{5}$ ).

[23] Raman spectra of the lower $\mathrm{SiO}_{2}$-rich coating are generally characterized by broad peaks, indicating that the coating material is amorphous (Figure 10). However, the spectra are inconsistent with previously reported Raman spectra of common and gem-quality opals [Ilieva et al., 2007;
Smallwood et al., 1997]. Instead, the spectrum of the $\mathrm{SiO}_{2}-$ rich coating most resembles that of a glass [Bertoluzza et al., 1982], and bears similarities to the spectrum of the basaltic substrate. The Raman spectrum of the basaltic glass features broad peaks at $522 \mathrm{~cm}^{-1}, 780 \mathrm{~cm}^{-1}$, and $971 \mathrm{~cm}^{-1}$, corresponding to the $\mathrm{O}-\mathrm{Si}-\mathrm{O}$ bending mode, symmetric stretch and asymmetric stretch, respectively [McMillan, 1984] (Figure 10). The position of the O-Si-O asymmetric stretch in silicate glasses is a function of the degree of polymerization; the $971 \mathrm{~cm}^{-1}$ position, as expected, corresponds to a metasilicate composition [McMillan, 1984]. In the silica coating, the asymmetric stretch band occurs around $965 \mathrm{~cm}^{-1}$, rather than $1060 \mathrm{~cm}^{-1}$ as previously documented for silica glass. The silica coating also features shifts to lower frequencies of the dominant bending mode $\left(479 \mathrm{~cm}^{-1}\right)$ and symmetric stretch mode $\left(706-728 \mathrm{~cm}^{-1}\right)$. The retention of the characteristic basalt $\mathrm{O}-\mathrm{Si}-\mathrm{O}$ asymmetric stretch position in the silica coating suggests that the silica is a residual product of leaching, and that as network-modifying cations were removed, the degree of polymerization was not affected.

[24] Some Raman spectra of silica-coated surfaces featured peaks at $1008 \mathrm{~cm}^{-1}$ and $1105 \mathrm{~cm}^{-1}$, corresponding to a member of the jarosite subgroup (Figure 10). This jarosite group member was also isolated as an independent phase within the silica coating (Figure 11). The particular species could not be definitively determined, but the Raman spectrum is most consistent with the potassium end-member, jarosite itself. The detection of jarosite in the silica coatings is not unexpected, given the high $\mathrm{SO}_{3}$ contents of the coating materials as determined by EPMA and common remote and in situ detections of jarosite in Hawaiian volcanic deposits [i.e., Morris et al., 2005; Guinness et al., 2007]. The spectral signature of olivine, characterized by strong peaks at $822 \mathrm{~cm}^{-1}$ and $854 \mathrm{~cm}^{-1}$, was also rarely detected associated with the coatings (Figure 11). This de-

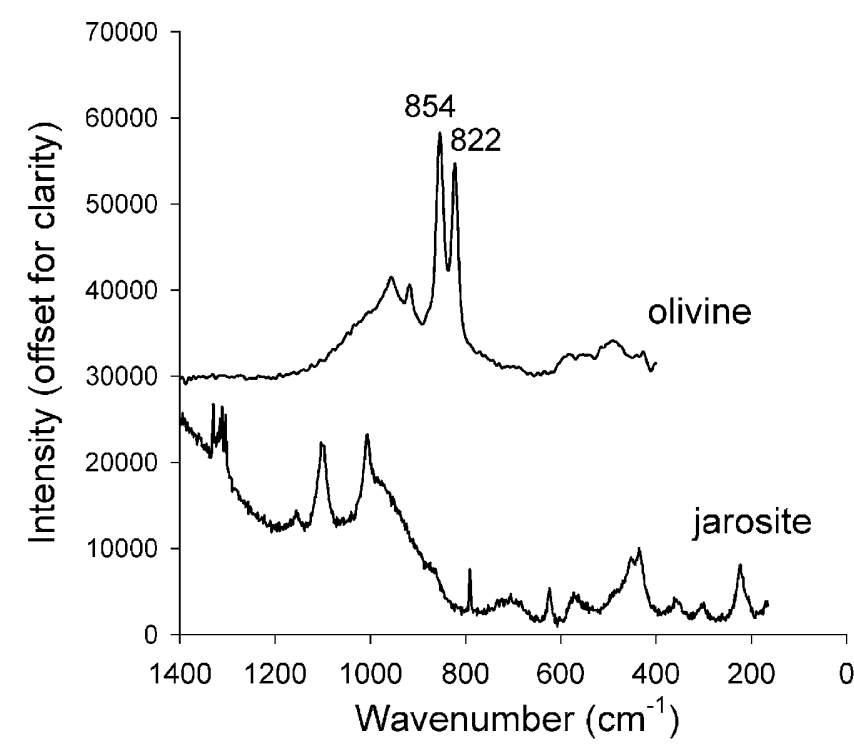

Figure 11. Raman spectra of other phases associated with the coatings. Olivine was rarely detected and may represent relict phenocrysts or occasional embedded ash particles. Jarosite was detected in association with the silica coating. 


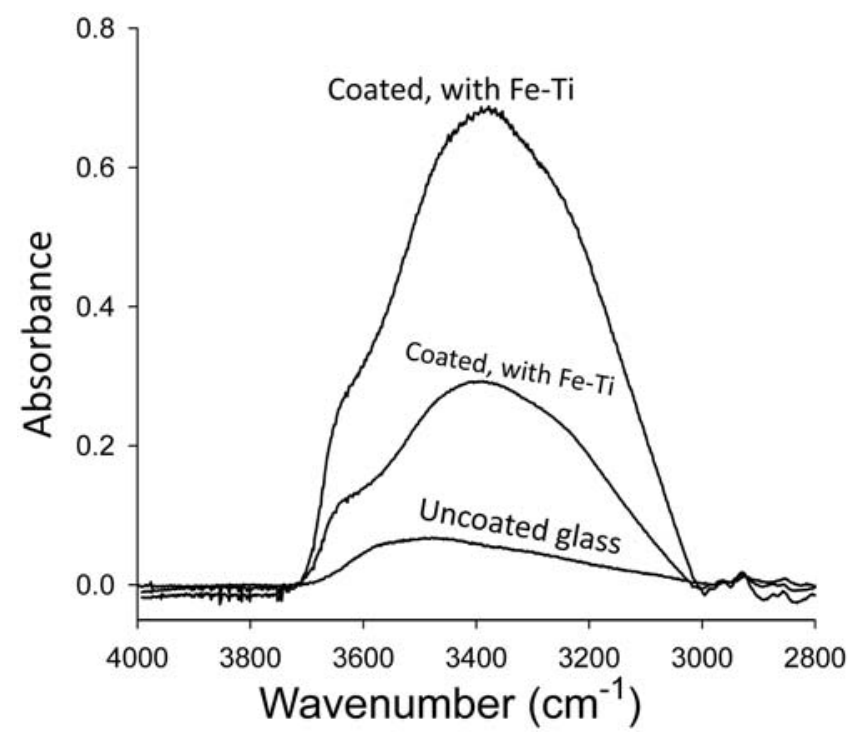

Figure 12. Transmission infrared spectra. The unaltered glass was determined to contain $0.01-0.10 \mathrm{wt} \%$ water. The coatings were calculated to contain $1.1-3.5 \%$ water.

tection is surprising because olivine has been determined to dissolve more quickly than basaltic glass at low $\mathrm{pH}$ [Hausrath et al., 2008]. The olivine may represent partially dissolved olivine phenocrysts, or it may derive from contamination by olivine-bearing ash.

\subsubsection{Transmission IR Spectroscopy}

[25] Transmission spectra of uncoated basalt wafers feature an asymmetric $\mathrm{OH}$ fundamental vibration peak at around $3543 \mathrm{~cm}^{-1}$ (Figure 12). Based on the value $67 \mathrm{~L} \cdot \mathrm{mol}^{-1} \cdot \mathrm{cm}^{-1}$ for molar absorptivity of water in basaltic glass [Stolper, 1982], the water content of the basalt was determined to vary between 0.01 and $0.10 \mathrm{wt} \%$. This water content was judged to be sufficiently low that it would not have an interfering impact on the measurement of the coating water content. The transmission spectrum of uncoated basalt was subtracted from coated basalt spectra in proportion to the thickness of basalt for each coated wafer.

[26] The transmission spectra of the coatings typically featured a broad, asymmetric peak centered at $\sim 3370 \mathrm{~cm}^{-1}$, with a shoulder at approximately $3635 \mathrm{~cm}^{-1}$ (Figure 12). This peak was typically well fit by the superposition of three Gaussians centered at $3230 \mathrm{~cm}^{-1}, 3413 \mathrm{~cm}^{-1}$ and $3633 \mathrm{~cm}^{-1}$; these bands likely correspond to the first overtone of the $\mathrm{H}_{2} \mathrm{O}$ bend, the $\mathrm{H}_{2} \mathrm{O}$ symmetric stretch, and $\mathrm{H}_{2} \mathrm{O}$ asymmetric stretch, respectively. Because the silica coating is so thin, attempts to quantify the proportions of $\mathrm{H}_{2} \mathrm{O}$ and $\mathrm{OH}$ in the opal using the combination bands at $\sim 4500 \mathrm{~cm}^{-1}$ and $5200 \mathrm{~cm}^{-1}$ (as in the work of Ohlhorst et al. [2001]) were unsuccessful. However, recent reports indicate that siliceous glasses hydrated at near-ambient temperature should contain little or no hydroxyl [Anovitz et al., 2008]. Using the value of integrated molar absorptivity for the $3570 \mathrm{~cm}^{-1}$ band given for $\mathrm{H}_{2} \mathrm{O}$ from Newman et al. [1986] $(26300 \pm 2200 \mathrm{~L}$ $\mathrm{mol}^{-1} \mathrm{~cm}^{-2}$ ), water content of the coating was determined to vary between 1.1 and $3.5 \mathrm{wt} \%$. Water content is a strong function of the presence or absence of a significant Fe-Ti oxide layer; analyzed spots with a pale coating layer present tended to have higher water content. This observation cannot be explained by high water contents in the Fe-Ti coating. Since the outer coating is only $\sim 1 \mu \mathrm{m}$ thick, explaining the excess water by assigning it to the $\mathrm{Fe}-\mathrm{Ti}$ layer would require an outer coating water content of up to $\sim 24 \mathrm{wt} \%$, an unreasonable value. A more reasonable explanation is that the silica coating has dehydrated since formation, and that the outer coating layer prevented or slowed dehydration. This dehydration could have occurred in the field after coating formation or in the laboratory since collection in 2003.

\subsection{Isotopic Characteristics}

[27] The oxygen isotope composition of the Fe-Ti oxide standards and the Hawaiian basalt substrate were determined via laser fluorination analysis. The measured $\delta^{18} \mathrm{O}_{\mathrm{SMOW}}$ values of the rutile and ilmenite were $29.7 \pm 0.3 \%$ and $5.8 \pm$ $0.22 \%$, respectively. The measured value of $\delta^{18} \mathrm{O}_{\text {SMOw }}$ of the basalt substrate was $5.1 \pm 0.07 \%$. This value of $\delta^{18} \mathrm{O}$ is comparable to most Hawaiian basaltic glasses [Eiler et al., 1996].

[28] SIMS oxygen isotope analyses of Fe-Ti oxide standards were successful and reproducible with standard deviations of $0.3-0.6 \%$. By comparing $\delta^{18} \mathrm{O}$ measured by laser fluorination to the SIMS analyses, instrumental mass fractionations (IMF) were calculated; for ilmenite, $1000 \ln \alpha_{\text {SIMS }}=$ $-0.1 \%$, and for rutile $1000 \ln \alpha_{\text {SIMS }}=-6.2 \%$. This difference in IMF is likely the result of a compositional matrix effect; iron content of oxides has previously been shown to strongly influence matrix effects [Riciputi et al., 1998; Eiler et al., 1997]. Assuming that the magnitude of the SIMS matrix effect in Fe-Ti oxides is, to first order, a function of composition along the $\mathrm{FeTiO}_{3}-\mathrm{TiO}_{2}$ join, the calculated fractionation for the composition of the Fe-Ti coating is $1000 \mathrm{ln}$ $\alpha_{\text {SIMS }}=-2.1 \%$. NanoSIMS analysis of the silica glass standard indicated an IMF for amorphous silica of $1000 \mathrm{ln}$ $\alpha_{\text {SIMS }}=22.5 \%$.

[29] Cameca $7 \mathrm{f}$ measurements of the Fe-Ti coating were performed on natural, unpolished coating surfaces, with a $\sim 40 \mu \mathrm{m}$ spot size (Figure 13a); NanoSIMS analyses of the silica coating were performed on polished thick sections, with a $\sim 6 \mu \mathrm{m}$ spot size (Figure 13b). SIMS and NanoSIMS analyses of the natural Hawaiian samples were commonly highly variable (Figure 13c and Table S1 of the auxiliary material). ${ }^{1}$ Most Cameca $7 f$ IMF-corrected measurements of $\delta^{18} \mathrm{O}$ of the Fe-Ti coating clustered around $14 \%$, with an outlier measurement at $25.3 \%$. NanoSIMS analyses of the silica coating showed a wide spread of $\delta^{18} \mathrm{O}$ values, with a cluster around 9\%. In both data sets, outlying measurements also featured low count rates, suggesting the effects of topography (up to tens of micrometers) on the natural sample surface. Based on this observation, the data sets were filtered by minimum count rate, producing more tightly clustered values; we focus our interpretations on these clusters comprising the majority of the data.

[30] Using the IMF previously calculated for the $\mathrm{Fe}-\mathrm{Ti}$ oxide composition and the mean of the clustered data, we determine $\delta^{18} \mathrm{O}_{\text {SMOW }}$ of the Fe-Ti coating to be $14.6 \pm$

\footnotetext{
${ }^{1}$ Auxiliary materials are available in the HTML. doi:10.1029/ 2009JE003473.
} 

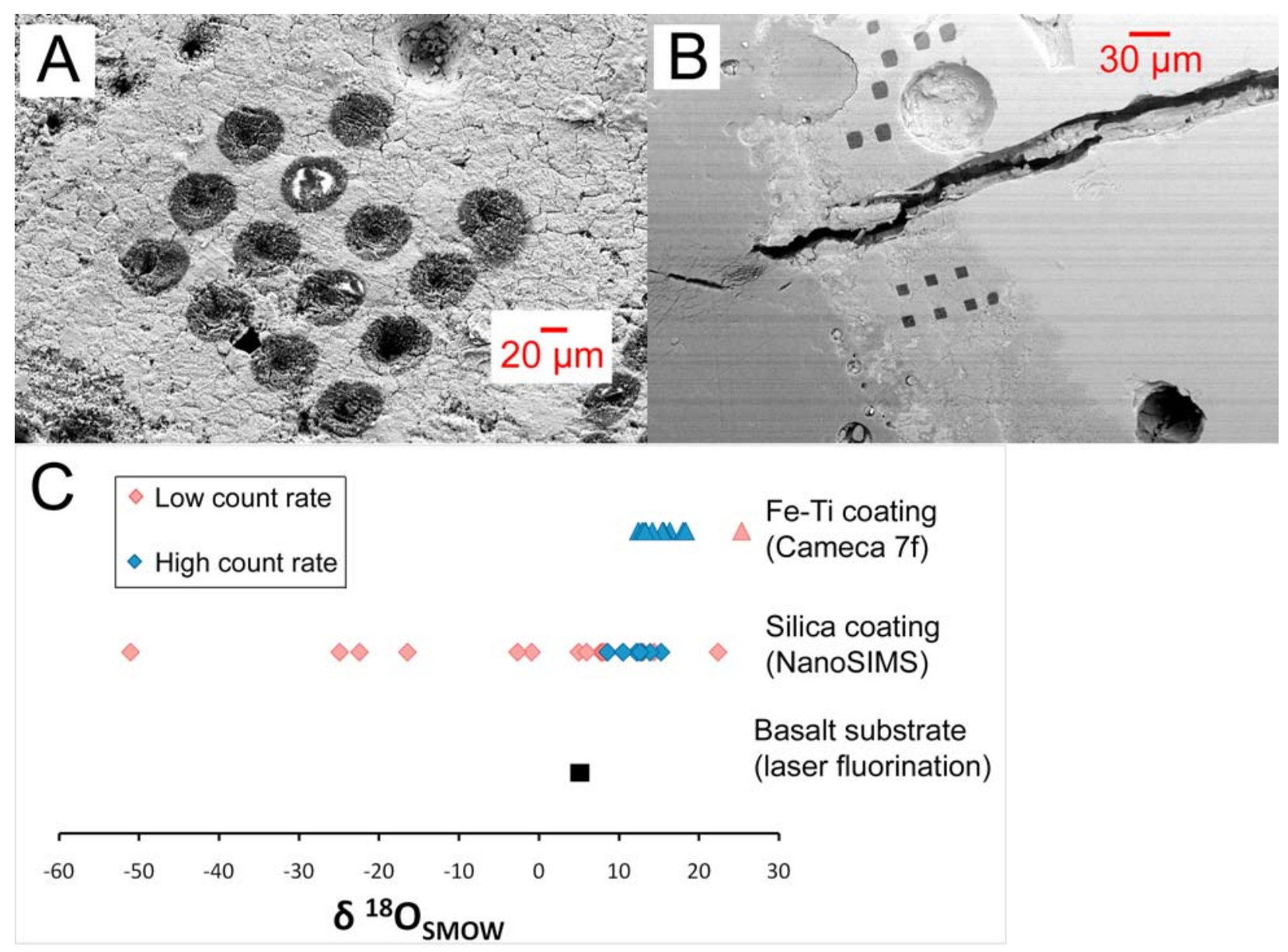

Figure 13. SIMS oxygen isotopic results. (a) Cameca $7 \mathrm{f}$ pits on natural coated surface for analysis of $\mathrm{Fe}-\mathrm{Ti}$ coating. (b) NanoSIMS pits of polished section for analysis of silica coating. (c) $\delta^{18} \mathrm{O}_{\text {SMOw }}$ measurements, poststandardization. Both data sets feature a wide spread of oxygen isotopic values, but many suffer from low count rates, indicating the effects of topography. Filtering the data by count rate produces a more tightly clustered set of measurements.

$2.1 \%$. Similarly, we calculate the $\delta^{18} \mathrm{O}_{\mathrm{SMOW}}$ of the silica coating layer to be $12.1 \pm 2.2 \%$ (Figure 13c).

\section{Discussion}

\subsection{Interpretation of Isotopic Data}

\subsubsection{Available Water Sources}

[31] As described above, the coating layers are progressively enriched in ${ }^{18} \mathrm{O}$ relative to the basalt substrate. The oxygen isotopic composition of the water from which the coating layers formed is unknown, but can be constrained by the $\delta^{18} \mathrm{O}$ of available water sources, which include rainwater, groundwater, and steam emitted at the vent and by the degassing flow. Precipitation collected in the Ka'u Desert between spring 1992 and spring 1993 varied between $-7.3 \%$ and $-3.9 \%$ [Scholl et al., 1995]. Groundwater collected from a Kilauea summit borehole in the same season had $\delta^{18} \mathrm{O}=-5.6 \%$ [Scholl et al., 1995]. Waters collected from fumaroles near the south rim of the Halemaumau pit crater had $\delta^{18} \mathrm{O}$ values of $-11.0 \%$ and $-4.3 \%$, indicating that these fumarolic waters are dominated by recycled meteoric water, with no magmatic water signal [Hinkley et al., 1995]. Therefore, the enriched coating $\delta^{18} \mathrm{O}$ cannot be the product of simple isotopic exchange between the basaltic substrate and available water sources. Below, we consider equilibrium and nonequilibrium formation scenarios consistent with the observed fractionations.

\subsubsection{Geothermometry}

[32] Under the assumption that the coatings formed in equilibrium with local meteoric water, we apply published geothermometers to estimate the temperatures associated with each layer. We consider the results of a silica-water geothermometer derived for amorphous silica [Kita et al., 1985] (KTM). Considering the observed range of meteoric $\delta^{18} \mathrm{O}$ and the measured silica coating $\delta^{18} \mathrm{O}$, the KTM thermometer indicates a temperature range of $369-440 \mathrm{~K}$ (Figure 14a). Another geothermometer derived for cryptocrystalline silica [Knauth and Epstein, 1976] produces a similar range of $353-425 \mathrm{~K}$. For the Fe-Ti oxide coating $\delta^{18} \mathrm{O}$, we consider the low-temperature anatase-water and rutile-water geothermometers published by Bird et al. [1993]. The observed fractionations correspond to a temperature range of $228-255 \mathrm{~K}$ for the anatase-water thermometer, and $211-237 \mathrm{~K}$ for the rutile-water geothermometer (Figure 14b).

[33] The geothermometry results described above indicate that the two coating layers cannot have formed at the same 


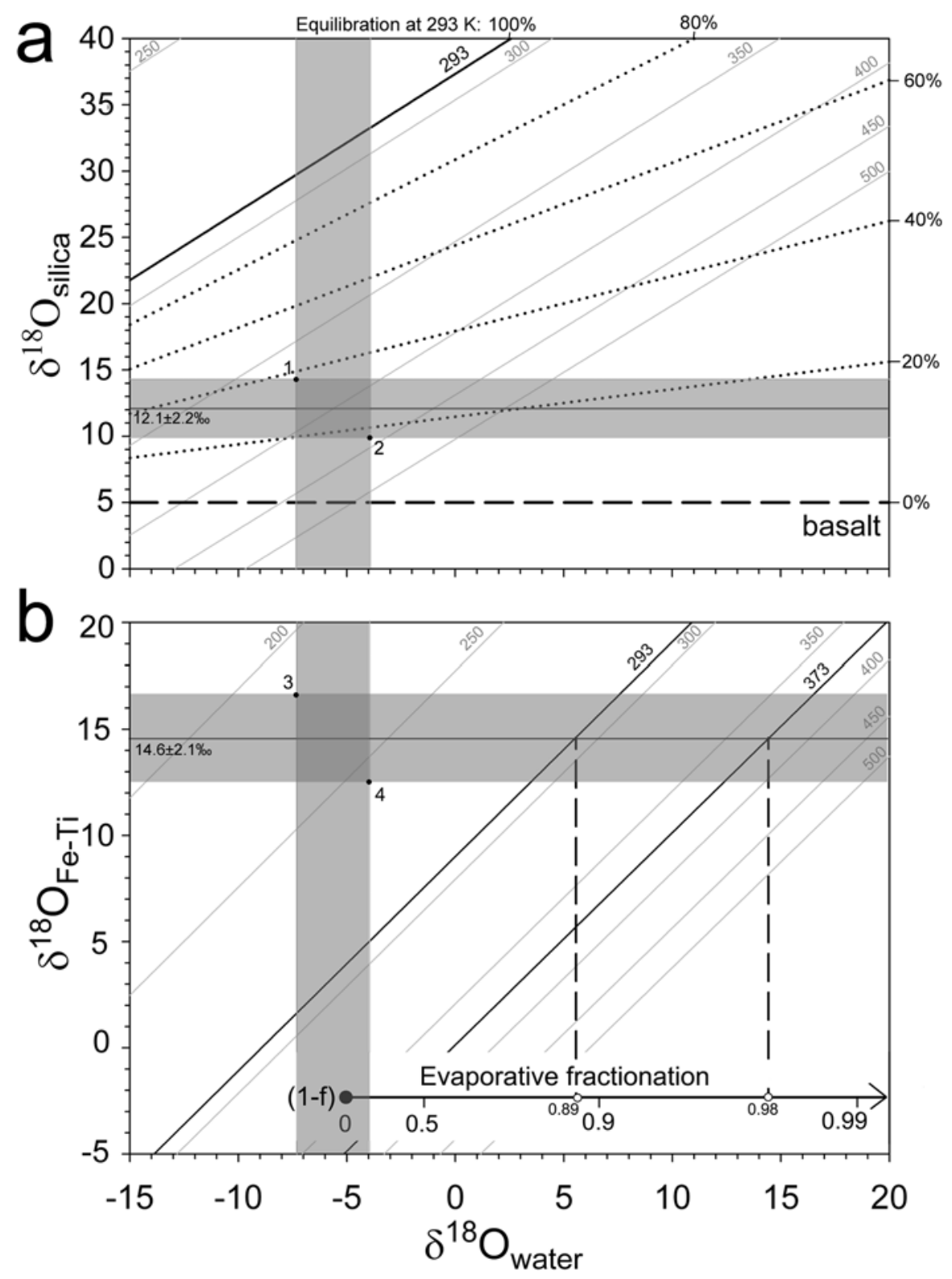

Figure 14. Geothermometry. In each plot, the horizontal shaded bar represents the SIMS measurement $( \pm 1 \sigma)$, and the vertical shaded bar represents the range of meteoric waters in the Ka'u Desert [Scholl et al., 1995]. (a) Silica coating. Solid contours are isotherms (in Kelvins) calculated for the amorphous silicawater geothermometer from Kita et al. [1985]. Dotted contours represent mixing at $293 \mathrm{~K}$ between the basaltic substrate ( $0 \%$ equilibration) and the equilibrium silica composition at $293 \mathrm{~K}(100 \%$ equilibration). The rectangle defined by points 1 and 2 represents the range in $\mathrm{T}$ for equilibrium formation (369$440 \mathrm{~K}$ ), and the range in $\mathrm{f}_{\text {equil }}$ for nonequilibrium formation (17-37\%). (b) Fe-Ti coating. Solid contours are isotherms (in Kelvins) calculated for the anatase-water geothermometer from Bird et al. [1993]. The rectangle defined by points 3 and 4 represents range in equilibrium temperature $(211-255 \mathrm{~K})$; these $\mathrm{T}$ are unreasonably low. The evaporative fractionation line defines conditions under which the Fe-Ti coating could have been deposited at ambient or elevated temperatures (see text).

temperature in equilibrium with water of meteoric composition. The geothermometer results suggest that the silica coatings formed well above ambient temperatures, near the boiling point of water. However, the assumption of mineralwater equilibrium during formation may be unrealistic in a low water-to-rock ratio environment, especially for the silica coating, which has chemical and textural characteristics consistent with a leaching residue. The observed $\delta^{18} \mathrm{O}_{\text {silica }}$ may also be explained by isotopic mixing between the basaltic substrate and meteoric water. For example, if the silica coating formed at ambient temperature $(293 \mathrm{~K})$, the observed $\delta^{18} \mathrm{O}_{\text {silica }}$ would indicate just $17-37 \%$ equilibration between 
the basaltic substrate and the water source (Figure 14a). Given that the silica probably did not achieve full equilibration with the water source, the temperatures measured by geothermometry then represent upper bounds on the temperature of formation.

[34] The assumption of mineral-water equilibrium is more reasonable for the $\mathrm{Fe}-\mathrm{Ti}$ coating, which was chemically deposited from solution. However, the unreasonably low, subfreezing temperatures indicated by the anatase geothermometer suggest that depositional solutions, originally of meteoric composition, were subject to evaporative fractionation. At $\mathrm{T}=373 \mathrm{~K}$, equilibrium liquid-water fractionation is described by $\alpha_{1-\mathrm{v}}=1.0051$ [Horita and Wesolowski, 1994]. Assuming equilibrium Rayleigh evaporation at $100 \%$ humidity, and neglecting Craig-Gordon effects [Craig et al., 1963; Criss, 1999], a fractionation of the required magnitude would require $\sim 98 \%$ evaporation ( $\mathrm{f}=0.02$ ) of the solution before precipitation of the Fe-Ti coating (Figure 14b). At ambient temperature, the observed fractionation requires $\sim 89 \%$ Rayleigh evaporation (assuming the same $\alpha_{1-\mathrm{v}}$ ).

[35] To summarize the above considerations, the $\delta^{18} \mathrm{O}$ measurements of the coating layers are consistent with both ambient and elevated temperatures. The silica coating $\delta^{18} \mathrm{O}$ indicates equilibrium formation temperatures as high as $440 \mathrm{~K}$, but this temperature represents an upper limit because of likely incomplete equilibration. The Fe-Ti coating equilibrated with water that had undergone extreme evaporative fractionation.

\subsection{Formation Mechanism}

\subsubsection{Field Relations}

[36] There is no universal mechanism for the formation of silica coatings [Dorn, 1998]; indeed, previous studies of Hawaiian silica coatings have illustrated that multiple mechanisms of formation operate on Hawaii alone. The presence of jarosite and the apparent mobility of $\mathrm{Fe}$ and $\mathrm{Ti}$ strongly suggest that the coatings on the 1974 flow are the product of acid-sulfate alteration. Field morphologies place constraints on the source of acidity. An obvious potential source of acidity is the nearby Kilauea Caldera, which typically emits 100-400 t SO 2 /day [Casadevall et al., 1987]. Magmatic $\mathrm{SO}_{2}$ is converted to sulfuric acid aerosol and is blown downwind up to several kilometers into the $\mathrm{Ka}$ ' $\mathrm{u}$ Desert, where it interacts with basaltic materials and produces amorphous silica [Schiffman et al., 2006]. In this region, silica deposits removed by physical weathering are continuously renewed [Schiffman et al., 2006]; thus, this model suggests steady growth of the silica layer over the 28 years between flow emplacement and collection. The regional "acid fog" model effectively describes much of the acid-sulfate alteration occurring in the Ka'u Desert, but it is inconsistent with several observations for the 1974 flow coatings. Areas on the pahoehoe flow where glass surfaces have spalled away show no apparent coating regrowth (Figure 2c). Silica coatings on the walls of interior vesicles require hot, syneruptional deposition (Figure 3g). Finally, it is difficult to explain the gradients in $\mathrm{Fe}-\mathrm{Ti}$ areal coverage away from the 1974 spatter ramparts with acidity derived solely from the main caldera.

[37] The Fe-Ti gradient away from the spatter ramparts suggest that the fissure vents that produced those ramparts were also important sources of acidic vapors. The post- eruptive gas emission history of the fissure vents is unknown; at the time our field work in 2002, activity had ceased. However, the vents certainly had their strongest gas emissions during and following the 1974 eruption; thus, our preferred interpretation involves coating formation over a period of weeks or months while the fissure vents were active. Oxygen isotopes constrain the temperature of formation of both coatings to around the boiling point of water or below. Some alteration, including the interior vesicle coatings, must have occurred at high temperature, implying short time scales. Such short time scales are reasonable; alteration by volcanic vapors can produce noticeable leaching and silica enrichment of basaltic glass in as little as an hour [Spadaro et al., 2002]. The majority of alteration may have occurred at ambient temperature, after the erupted basalt had cooled but before the vents had stopped steaming. The main caldera may have also contributed acidity. The onset of the 1983 P'u O'o eruption, $20 \mathrm{~km}$ away from Kilauea Caldera on the east rift zone, was accompanied by a $\sim 2 \times$ increase in $\mathrm{SO}_{2}$ emissions from the main caldera [Casadevall et al., 1987]; similarly, the onset of the 1974 eruption along the SW rift zone was likely accompanied by a jump in gas flux at the caldera. A weakness of this interpretation is that our sampling was too sparse to identify variations in the thickness of the silica layer away from the vents. Additional field work is required to identify and characterize any thickness gradients and gauge the relative importance of regional, calderaderived vapors and local, fissure vent-derived vapors.

\subsubsection{Silica Coating}

[38] We consider two classes of microscale formation pathways for the 1974 Ka'u Desert silica coatings: (1) direct deposition and (2) residual leaching and dissolution.

\subsubsection{Direct Deposition}

[39] A direct depositional mechanism requires an external source of silica and a method for chemical deposition on the basalt surface. Proposed solid sources for the silica in Hawaiian silica coatings include phytolith-bearing atmospheric dust [Farr and Adams, 1984] and windblown volcanic ash and tephra [Curtiss et al., 1985]. These windblown materials then undergo partial dissolution during wetting events, and amorphous silica precipitates [Curtiss et al., 1985]. This mechanism is unlikely for the formation of the 1974 coatings, which are laterally homogenous and show no evidence of embedded clasts. External silica can be derived by dissolution of the rock substrate and transportation in solution as monosilicic acid $\left(\mathrm{Si}(\mathrm{OH})_{4}\right)$ [Dorn, 1998], or as colloidal silica [Krauskopf, 1956]. Dissolved silica is the primary silica source for more volumetrically significant deposits like siliceous sinters [Rodgers et al., 2002]. Silica may also be carried in steam, but its solubility is low at near-surface pressures [Macdonald, 1944; Brady, 1953]. $\mathrm{SiF}_{4}$ has been proposed as a volatile gaseous phase present during the cooling of Hawaiian basalt flows, but such volatilization produces local Si depletions, not enrichments [White and Hochella, 1992]; therefore, a vapor depositional mechanism seems unlikely. We restrict further consideration to depositional mechanisms involving aqueous solution.

[40] The strongest evidence supporting a depositional mechanism is the sharp boundary between the silica coating and the basaltic substrate, and the lack of an obvious chemical gradient within the glass near the coating. However, chemical boundary layers produced by short-term 
leaching of silicate glasses can be just tens of nanometers wide, undetectable at the spatial resolution of EPMA [Smets and Lommen, 1982]. The presence of an apparently sharp boundary, therefore, does not prove a depositional mechanism. Other observations are inconsistent with deposition. The first mineral phase deposited in hydrothermal sinter environments is opal-A [Herdianita et al., 2000]; the absence of spheroidal texture in the silica layer, together with Raman spectroscopic evidence, indicate that opal-A is not present. Amorphous, nonopaline silica can be deposited from solution [Fournier and Rowe, 1966], but opal is the norm in depositional environments. Finally, the coating, in places, directly overlies near-surface vesicles with no basaltic substrate underneath (Figure 3b). The coatings could not have been deposited here, as there was no surface on which to deposit. In other places, vertical and horizontal walls of surface vesicles feature coatings of uniform thickness, an implausible geometry for a depositional scenario (Figure 3c). Based on these observations, we do not favor a depositional mechanism for the formation of the silica coatings.

\subsubsection{Residual Leaching and Dissolution}

[41] The silica coating might also have formed through alteration of the basaltic glass substrate, either by leaching (by hydrothermal fluids or meteoric water), or by total dissolution and reprecipitation. Under low $\mathrm{pH}$ conditions (2-3), $\mathrm{Si}^{4+}$ is relatively insoluble in solution and lower valence basaltic cations $\left(\mathrm{Mg}^{2+}, \mathrm{Ca}^{2+}, \mathrm{Al}^{3+}, \mathrm{Na}^{+}\right)$are mobile and easily exchanged for protons in solution; thus, basalt leaching could leave behind a silica-enriched layer [El-Shamy et al., 1972; Minitti et al., 2007]. Highly acidic conditions have frequently been invoked for the genesis of Hawaiian alteration products [e.g., Schiffman et al., 2006; Macdonald, 1944]. Because basalt weathering consumes acidity, a leaching mechanism must operate either in an environment with a high water-torock ratio or with continuously renewed acidity [Minitti et al., 2007].

[42] The observations presented in this study are most consistent with a leaching formation mechanism for the 1974 silica coating; given the presence of jarosite, this leaching is likely facilitated by acid-sulfate alteration. The hypothesis of a residual nature for the silica layer is supported by its porous texture, low concentrations of elements in basaltic proportions, and glass-like mineralogy as determined by Raman spectroscopy. We have not been able to definitively identify the leaching agent; vapor alteration has been proposed as a mechanism for the production of secondary silica in volcanic environments [Tosca et al., 2004], but liquids are likely required for the removal of lower valence cations from the system [Squyres et al., 2008].

[43] The above evidence indicates that acid-sulfate leaching is the dominant mechanism involved in the coating formation; however, other mechanisms must also be operating to explain the lack of obvious diffusive profiles in leached elements and the enriched $\delta^{18} \mathrm{O}$ signature. Oxygen diffusion through glass is exceedingly slow at ambient and epithermal temperatures [e.g., Rawal and Cooper, 1979], so any enrichment suggests that oxygen transport was facilitated by small-scale dissolution and reprecipitation. Such small-scale dissolution might erase concentration gradients within the coating. In addition, thin silica deposits observed on the walls of interior vesicles are likely the product of vapor deposition.
Thus, although silica was primarily immobile during leaching, there is evidence for silica mobility on length scales of a few micrometers.

\subsubsection{Fe-Ti Coating}

[44] The observations presented in this study provide considerable constraints on the origin of the Fe-Ti coating layer. The spheroidal aggregate texture necessitates a depositional mechanism; the varying spherule size (Figure $3 \mathrm{f}$ ) is likely a result of numerous environmental factors, including variable water-to-rock ratio and $\mathrm{pH}$ of solution. Vapor deposition of Fe-Ti oxides has been recorded in stalactites within a lava tube [Baird et al., 1985], and Ti has been detected in measurable quantities in aerosols in volcanic plumes [Hinkley, 1991]. However, it is difficult to explain the relative homogeneity of the Fe-Ti coating and the evaporative oxygen isotopic signature with a vapor depositional mechanism; therefore, our preferred explanation involves chemical deposition of the $\mathrm{Fe}-\mathrm{Ti}$ oxides from aqueous solution.

[45] The source of the chemical constituents of the Fe-Ti coating and their transport in solution are not fully understood. The mobility of $\mathrm{Ti}$ in sedimentary systems near neutral $\mathrm{pH}$ is limited, often less than $1 \mu \mathrm{m}$ [Tilley and Eggleton, 2005]. Fe and Ti were likely released into solution by chemical weathering of basaltic glass or accessory phases such as titanomagnetite. The high areal proportions of Fe-Ti coating coverage near the vents was achieved either by thicker leaching zones on the surfaces of erupting basalts (although thicker silica coatings have not been observed), or by leaching of basalts around the vent walls and transport of dissolved basaltic cations in volcanic fluids. Titanomagnetites have been shown to dissolve readily at low $\mathrm{pH}$ [Arlauckas and McLennan, 2005; Tosca et al., 2004]. However, Fe-Ti oxides tend to dissolve nonstoichiometrically, with $\mathrm{Ti}$ being considerably less mobile in solution than $\mathrm{Fe}$ [Arlauckas and McLennan, 2005]. There are two possible explanations for high $\mathrm{Ti} / \mathrm{Fe}$ ratios in the coating. One possibility is that Ti was transported in solution as hydroxy-sulfate complexes like $\mathrm{Ti}(\mathrm{OH}) \mathrm{SO}_{4}^{2+}$ [Agapova et al., 1989] or as hydroxy-halide complexes like $\mathrm{Ti}(\mathrm{OH})_{2} \mathrm{~F}_{4}^{2-}[$ Barsukova et al., 1979]. NanoSIMS mapping indicated $F$ enrichment in the Fe-Ti layer (Figure 7), and Kilauean gases are $\mathrm{F}^{-}$and $\mathrm{Cl}^{-}$ bearing [Naughton, 1980]. If complexation did occur, Ti might be transported for large distances before deposition. A second explanation for the high $\mathrm{Ti} / \mathrm{Fe}$ ratios is that the $\mathrm{Ti}$ and $\mathrm{Fe}$ were carried in solution for very short distances (i.e., micrometers) before precipitation, such that $\mathrm{Ti}$ could not fractionate out. This scenario is supported by the high concentrations of $\mathrm{P}$ in the Fe-Ti coating, another highly immobile element found in the basaltic glass. The formation of the Mauna Ulu Fe-Ti coating, which has a higher and more variable $\mathrm{Fe} / \mathrm{Ti}$ ratio, must have featured longer characteristic transport distances and less efficient transport of $\mathrm{Ti}$ in solution.

[46] The depositional texture and stratigraphic position of the Fe-Ti coating requires that it formed concurrently with or after silica coating formation. The enriched $\delta^{18} \mathrm{O}$ is consistent with deposition near ambient temperature from a highly evaporated solution. The poor crystallinity of the Fe-Ti layer is also consistent with low-temperature deposition [Hsu et al., 1986], suggesting a depositional window after basalt cooling but before vent activity ceased. The 


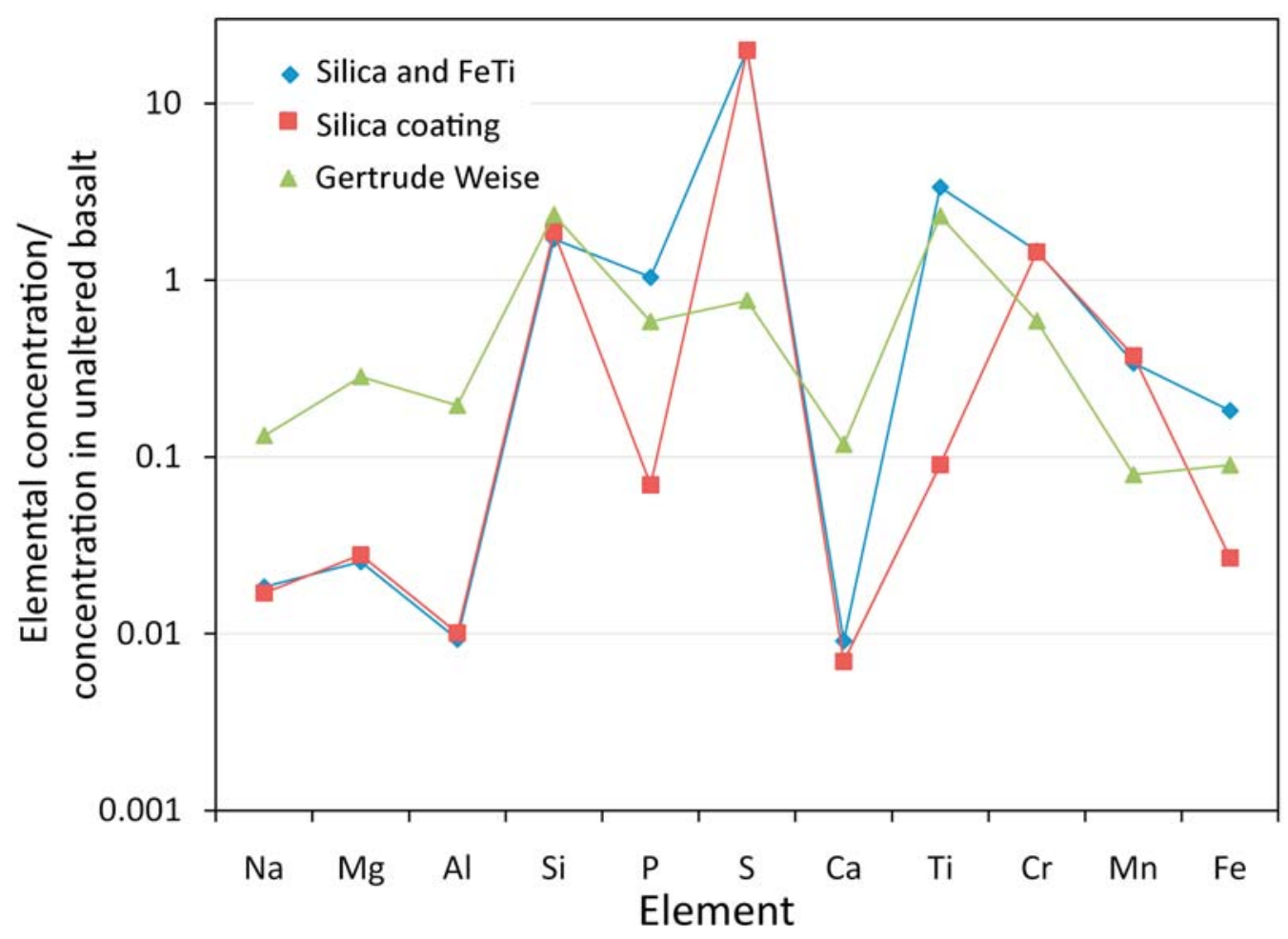

Figure 15. Composition of silica-rich materials from Hawaii and Mars relative to their respective unaltered basalt composition. The Gertrude Weise ratios are calculated relative to Adirondack class basalt [Ming et al., 2006]. "Silica coating" refers to the end-member composition of the silica layer alone; "Silica and FeTi" was calculated by a weighted average of the silica end-member and the Fe-Ti oxide end-member (10:1).

simplest and most general explanation consistent our observations is that both coating materials formed from an isotopically evolving water body in a single chain of events. Acidic fluids leached the upper layer of basalt glass, leaving a silica-enriched layer behind and releasing $\mathrm{Fe}$ and $\mathrm{Ti}$ into solution. The solution evaporated, precipitating the $\mathrm{Fe}-\mathrm{Ti}$ oxide overlying the silica.

\section{Implications for Mars}

\subsection{Silica Deposits at Gusev Crater}

[47] No Martian silica deposit has been studied in greater detail than those discovered at Gusev Crater. These deposits consist of light-toned soils and nodular outcrops in the vicinity of Home Plate, an $\sim 80 \mathrm{~m}$ wide ovate landform featuring platy layered outcrops interpreted as altered volcanic tuff deposits [Squyres et al., 2007; Arvidson et al., 2008]. The most silica-enriched soil site, Gertrude Weise, is composed of over $90 \% \mathrm{SiO}_{2}$ [Squyres et al., 2008]. These soils are sometimes associated with ferric sulfates (e.g., Tyrone), but Gertrude Weise is also highly depleted in sulfur. MiniTES spectra of the high-silica soils contain vibrational absorption features at $475 \mathrm{~cm}^{-1}$ and $1110 \mathrm{~cm}^{-1}$ consistent with the Si-O stretching and bending modes in opal-A [Squyres et al., 2008; Michalski et al., 2003]. The Home Plate high-silica materials, like the Ka'u Desert silica coatings, have been interpreted as the products of acid-sulfate alteration, but it is unclear whether they are residual or were transported and deposited as a siliceous sinter [Squyres et al.,
2008]. The occurrence of the high-silica materials in soils suggests the deposits were subjected to postdepositional reworking, probably under a dry atmosphere [Squyres et al., 2008].

[48] Compositional comparison between the Gertrude Weise (GW) soil sample and the 1974 silica coatings may provide additional clues about Martian alteration conditions. The bulk composition of the Hawaiian coating material was estimated by weighting electron microprobe analyses of the silica coating and the Fe-Ti coating in a 10:1 ratio, roughly corresponding to their respective thicknesses. Elemental ratios of each alteration product to their respective unaltered basalt indicate that both $\mathrm{GW}$ and the coating materials are enriched in $\mathrm{Si}$ and $\mathrm{Ti}$ and strongly depleted in $\mathrm{Na}, \mathrm{Mg}, \mathrm{Al}$, $\mathrm{Mn}$, and $\mathrm{Fe}$ (Figure 15). The depletions of basaltic elements are more extreme in the Hawaiian samples than in GW, suggesting unusually efficient leaching or possible subsequent remobilization events. The most noticeable differences in major element chemistry between the two deposits are in $\mathrm{S}, \mathrm{P}$, and $\mathrm{Cr}$. The Hawaiian coatings are strongly enriched in S; Gertrude Weise is moderately depleted in S relative to unaltered basalt. This apparent depletion is partially the result of high initial S concentrations in Martian basalt [Ming et al. 2006], but the depletion also indicates that $\mathrm{GW}$ is a late stage leaching product. $\mathrm{P}$ and $\mathrm{Cr}$ are moderately enriched in the Hawaiian coatings, but are moderately depleted in GW. These two elements are generally immobile in solution, so the GW depletion may indicate longer characteristic transport distances than the Hawaiian Fe-Ti coatings. 
[49] A major difference in the character of the two deposits is the volume of alteration. The Ka'u Desert coatings in this study are only $\sim 10 \mu \mathrm{m}$ thick, whereas observations at Gusev Crater indicate outcrop-scale alteration at least several $\mathrm{cm}$ deep [Squyres et al., 2008]. This difference in alteration volume is likely a function of both the length and intensity of alteration. The coatings on the 1974 flow formed in no longer than 30 years, and likely in a much shorter time period; older coatings on Hawaiian lava flows are often thicker, up to several hundred micrometers [Farr and Adams, 1984; Minitti et al., 2007]. Hawaiian samples collected near fumaroles at Halema'uma'u Crater and Sulfur Bank, where exposure to acidic fluids is more consistent and intense, show volume alteration similar to that seen at Home Plate [Macdonald, 1944; Morris et al., 2000]. Volume alteration may also indicate percolation of fluids and vapors through a substrate along fractures and grain boundaries [Morris et al., 2000], instead of only surface interaction as observed on the 1974 flow. Therefore, the morphology and distribution of the highsilica materials near Home Plate suggests long-lived (decades to centuries), intense acid-sulfate alteration in close proximity to a hydrothermal or fumarolic vent.

\subsection{Global Processes}

[50] Orbital detections of $\mathrm{Si}-\mathrm{OH}$ and $\mathrm{Si}-\mathrm{O}$ vibrations in thermal infrared spectra and VNIR reflectance spectra suggest that opaline silica may be present on Mars at much larger spatial scales than represented by the Home Plate deposits. Opaline silica, as identified by CRISM, is associated with light-toned bedded deposits in Valles Marineris that extend for tens or hundreds of kilometers [Milliken et al., 2008]. These spectral detections of opaline silica are often associated with jarosite, a robust indicator of acidsulfate formation conditions. The volumetric extent of these secondary minerals in the deposits is unknown; the spectral signature could be produced by volume-altered ash deposits [Milliken et al., 2008], or thin silica coatings or weathering rinds, which mask the spectral signature of their unaltered substrate [Seelos et al., 2010; Minitti et al., 2007]. Regardless of the extent of alteration in these layered units, a formation mechanism similar to that of the Hawaiian coating seems unlikely. Alteration on the 1974 Kilauea flow occurred over a spatial domain of several kilometers; the source of acidity for this alteration was one or several volcanic vents. Pervasive volcanic alteration in distinct bedded layers over several hundred kilometers would likely require intense regional volcanism with many active vents. No obvious volcanic vents have been observed via HiRISE imagery in the area of these deposits, suggesting an aqueous, nonvolcanic origin [Milliken et al., 2008]. Mechanisms more likely to produce pervasive regional opaline silica include deposition from an evaporating, acidic water body and groundwater infiltration. Elsewhere on Mars, hydrated silica has been detected in highlands craters in the Nili Fossae region, often in association with other hydrated minerals including phyllosilicates and zeolites [Ehlmann et al., 2009]. These mineral assemblages indicate regional hydrothermal or low-grade metamorphic alteration at near-neutral $\mathrm{pH}$, implying an environment dissimilar to the Ka'u Desert. The CRISM silica detections indicate that silica formation on Mars, as on Earth, occurs over a wide range of water-torock ratios and environmental conditions.
[51] In addition to the targeted spectral detections described above, hydrated silica coatings have been suggested as regionally or globally occurring phenomena to explain more widespread spectral observations. Surface Type 2, a unit defined by TES spectra that characterizes most of the dark surfaces in the Martian northern lowlands, has a spectral component corresponding to hydrous or high-silica glass [Bandfield et al., 2000]. This spectral component is consistent with silica coatings capping unaltered basalt [Kraft et al., 2003]. Silica coatings have also been invoked as a global phenomenon to explain muting of the highcalcium pyroxene signature in CRISM spectra from Hesperian compositionally distinct ejecta [Skok et al., 2008]. If silica coatings do occur on a global scale on the Martian surface, a volcanic acid-sulfate origin as described in this paper is unlikely; volcanic vapors probably only act as alteration agents on the spatial scale of kilometers. Any plausible formation mechanism involves water, but the putative widespread occurrence of silica coatings in the northern lowlands does not distinguish between mechanisms involving an ancient ocean [Head et al., 1999] and mechanisms involving thin film wetting and alteration [Kraft et al., 2004].

[52] Acknowledgments. This work was supported by funding from NASA grants NAG5-12684 to B. Jolliff and NNX06AB20G to G. Rossman as well as Gordon and Betty Moore Foundation funding for the Caltech Center for Microanalysis to J. Eiler. The manuscript was significantly improved by the input of Kim Seelos and an anonymous reviewer. We thank Chi Ma for assistance with collection of SEM imagery, Naomi Levin for assistance with laser fluorination measurements, and Yunbin Guan for assistance in the use of the NanoSIMS and Cameca $7 \mathrm{f}$.

\section{References}

Abrams, M., E. Abbott, and A. Kahle (1991), Combined use of visible, reflected infrared, and thermal infrared images for mapping Hawaiian lava flows, J. Geophys. Res., 96, 475-484, doi:10.1029/90JB01392.

Agapova, G., I. Modnikov, and Y. Shmariovich (1989), Experimental study of the behavior of titanium in hot sulfide-carbonate solutions, Int. Geol. Rev., 31, 4424-4430.

Anovitz, L. M., D. R. Cole, and M. Fayek (2008), Mechanisms of rhyolitic glass hydration below the glass transition, Am. Mineral., 93, 1166-1178, doi:10.2138/am.2008.2516.

Arlauckas, S., and S. McLennan (2005), Dissolution rates and weathering products of iron-titanium oxides: $\mathrm{PH}$ and temperature dependence, Lunar Planet. Sci., XXXVI, Abstract 2011.

Arvidson, R. E., et al. (2008), Spirit Mars Rover Mission to the Columbia Hills, Gusev Crater: Mission overview and selected results from the Cumberland Ridge to Home Plate, J. Geophys. Res., 113, E12S33, doi:10.1029/2008JE003183.

Baird, A. K., D. C. Mohrig, and E. E. Welday (1985), Vapor deposition in basaltic stalactites, Kilauea, Hawaii, Lithos, 18, 151-160, doi:10.1016/ 0024-4937(85)90016-7.

Bandfield, J. L., V. E. Hamilton, and P. E. Christensen (2000), A global view of Martian surface composition from MGS-TES, Science, 287, 1626-1630, doi:10.1126/science.287.5458.1626.

Barsukova, M. L., V. A. Kuznetsov, V. A. Dorofeyeva, and L. I. Khodakovskiy (1979), Measurement of the solubility of rutile $\mathrm{TiO}_{2}$ in fluoride solutions at elevated temperatures, Geochem. Int., 16(4), 41-49.

Bell, J. F., III, R. V. Morris, and J. B. Adams (1993), Thermally altered palagonitic tephra: A spectral and process analog to the soil and dust of Mars, J. Geophys. Res., 98, 3373-3385, doi:10.1029/92JE02367.

Bertoluzza, A., C. Fagnano, M. A. Morelli, V. Gottardi, and M. Guglielmi (1982), Raman and infrared spectra on silica gel evolving toward glass, J. Non Cryst. Solids, 48, 117-128, doi:10.1016/0022-3093(82)90250-2.

Bird, M. I., F. J. Longstaffe, and W. S. Fyfe (1993), Oxygen-isotope fractionation in titanium-oxide minerals at low temperature, Geochim. Cosmochim. Acta, 57, 3083-3091, doi:10.1016/0016-7037(93)90295-8.

Brady, E. L. (1953), Chemical nature of silica carried by steam, J. Phys. Chem., 57, 706-710, doi:10.1021/j150508a025. 
Casadevall, T. J., J. B. Stokes, L. P. Greenland, L. L. Malinconico, J. R. Casadevall, and B. T. Furukawa (1987), $\mathrm{SO}_{2}$ and $\mathrm{CO}_{2}$ emission rates at Kilauea Volcano, 1979-1984, in Volcanism in Hawaii, edited by R. W. Decker et al., chap. 29, U.S. Geol. Surv. Prof. Pap., 1350, 771-780. Christensen, P. R., et al. (2004), Initial results from the Mini-TES Experiment in Gusev Crater from the Spirit Rover, Science, 305, 837-841, doi:10.1126/science.1100564.

Craig, H., L. J. Gordon, and Y. Horibe (1963), Isotopic exchange effects in the evaporation of water, J. Geophys. Res., 68, 5079-5087.

Crisp, J., A. Kahle, and E. A. Abbott (1990), Thermal infrared spectra character of Hawaiian basaltic glasses, J. Geophys. Res., 95, 21,65721,669, doi:10.1029/JB095iB13p21657.

Criss, R. E. (1999), Principles of Stable Isotope Distribution, 254 pp. Oxford Univ. Press, New York.

Curtiss, B., J. B. Adams, and M. S. Ghiorso (1985), Origin, development and chemistry of silica-alumina rock coatings from the semi-arid regions of the island of Hawaii, Geochim. Cosmochim. Acta, 49, 49-56, doi:10.1016/0016-7037(85)90190-5.

Darragh, P. J., A. J. Gaskin, B. C. Terrell, and J. V. Sanders (1966), Origin of precious opal, Nature, 209, 13-16, doi:10.1038/209013a0.

Dorn, R. I. (1998), Rock Coatings, 444 pp., Elsevier, New York.

Ehlmann, B. L., et al. (2009), Identification of hydrated silicate minerals on Mars using MRO-CRISM: Geologic context near Nili Fossae and implications for aqueous alteration, J. Geophys. Res., 114, E00D08, doi:10.1029/2009JE003339.

Eiler, J. M., K. A. Farley, J. W. Valley, A. W. Hofmann, and E. M. Stolper (1996), Oxygen isotope constraints on the sources of Hawaiian volcanism, Earth Planet. Sci. Lett., 144, 453-468, doi:10.1016/S0012-821X (96)00170-7.

Eiler, J. M., C. Graham, and J. W. Valley (1997), SIMS analysis of oxygen isotopes: Matrix effects in complex minerals and glasses, Chem. Geol. 138, 221-244, doi:10.1016/S0009-2541(97)00015-6.

El-Shamy, T. M., J. Lewins, and R. W. Douglas (1972), The dependence of the $\mathrm{pH}$ of the decomposition of glasses by aqueous solutions, Glass Tech., 13, 81-87.

Evans, D. L., T. G. Farr, and J. B. Adams (1981), Spectral reflectance of weathered terrestrial and Martian surfaces, Proc. Lunar Planet. Sci. Conf., 12th, 1473-1479.

Farmer, J. D., and D. J. Des Marais (1999), Exploring for a record of ancient Martian life, J. Geophys. Res., 104, 26,977-26,995, doi:10.1029/ 1998JE000540.

Farr, T. G., and J. B. Adams (1984), Rock coatings in Hawaii, Geol. Soc. Am. Bull., 95, 1077-1083, doi:10.1130/0016-7606(1984)95<1077: $\mathrm{RCIH}>2.0 . \mathrm{CO} ; 2$.

Fournier, R. O., and J. J. Rowe (1966), The deposition of silica in hot springs, Bull. Volcanol., 29, 585-587, doi:10.1007/BF02597179.

Gu, Z., A. Fujishima, and O. Sato (2002), Fabrication of high-quality opa films with controllable thickness, Chem. Mater., 14, 760-765, doi: $10.1021 / \mathrm{cm} 0108435$.

Guinness, E. A., R. Arvidson, B. Jolliff, K. Seelos, F. Seelos IV, D. Ming, R. Morris, and T. Graff (2007), Hyperspectral reflectance mapping of cinder cones at the summit of Mauna Kea and implications for equivalen observations on Mars, J. Geophys. Res., 112, E08S11, doi:10.1029/ 2006JE002822.

Hausrath, E. M., A. K. Navarre-Sitchler, P. B. Sak, C. I. Steefel, and S. L. Brantley (2008), Basalt weathering rates on Earth and the duration of liquid water on the plains of Gusev Crater, Mars, Geology, 36, 67-70, doi:10.1130/G24238A.1.

Head, J. W., III, H. Hiesinger, M. A. Ivanov, M. A. Kreslavsky, S. Pratt, and B. J. Thomson (1999), Possible ancient oceans on Mars: Evidence from Laser Orbiter Altimeter data, Science, 286, 2134-2137, doi:10.1126/science.286.5447.2134

Herdianita, N. R., P. R. L. Browne, K. A. Rodgers, and K. A. Campbell (2000), Mineralogical and textural changes accompanying ageing of silica sinter, Miner. Deposita, 35, 48-62, doi:10.1007/s001260050005.

Hinkley, T. K. (1991), Distribution of metals between particulate and gaseous forms in a volcanic plume, Bull. Volcanol., 53, 395-400, doi:10.1007/BF00280229.

Hinkley, T. K., J. E. Quick, R. T. Gregory, and T. M. Gerlach (1995), Hydrogen and oxygen isotopic composition of waters from fumaroles at Kilauea summit, Hawaii, Bull. Volcanol., 57, 44-51, doi:10.1007/ BF00298706.

Horita, J. D., and D. J. Wesolowski (1994), Liquid-vapor fractionation of oxygen and hydrogen isotopes of water from the freezing to the critica temperature, Geochim. Cosmochim. Acta, 58, 3425-3437, doi:10.1016/ 0016-7037(94)90096-5.

Hsu, L. S., R. Rujkorakarn, J. R. Sites, and C. Y. She (1986), Thermally induced crystallization of amorphous-titania films, J. Appl. Phys., 59, 3475-3480, doi:10.1063/1.336817.
Ilieva, A., B. Mihailova, Z. Tsintsov, and O. Petrov (2007), Structural state of microcrystalline opals: A Raman spectroscopic study, Am. Mineral., 92, 1325-1333, doi:10.2138/am.2007.2482.

Kita, I., S. Taguchi, and O. Matsubaya (1985), Oxygen isotope fractionation between amorphous silica and water at $34-93^{\circ} \mathrm{C}$, Nature, 314 , 83-84, doi:10.1038/314083a0.

Knauth, L. P., and S. Epstein (1976), Hydrogen and oxygen isotope ratios in nodular and bedded cherts, Geochim. Cosmochim. Acta, 40, 10951108, doi:10.1016/0016-7037(76)90051-X.

Kraft, M. D., J. R. Michalski, and T. G. Sharp (2003), Effects of pure silica coatings on thermal emission spectra of basaltic rocks: Considerations for Martian surface mineralogy, Geophys. Res. Lett., 30(24), 2288, doi:10.1029/2003GL018848.

Kraft, M. D., J. R. Michalski, and T. G. Sharp (2004), High-silica rock coatings: TES surface-type 2 and chemical weathering of Mars, Lunar Planet. Sci., XXXV, Abstract 1936.

Krauskopf, K. B. (1956), Dissolution and precipitation of silica at low temperatures, Geochim. Cosmochim. Acta, 10, 1-26, doi:10.1016/0016-7037 (56)90009-6.

Liu, L., and T. P. Mernagh (1992), Phase transitions and Raman spectra of anatase and rutile at high pressures and room temperature, Eur. J. Mineral. 4, 45-52.

Macdonald, G. A. (1944), Solfataric alteration of rocks at Kilauea volcano, Am. J. Sci., 242, 496-505.

McLennan, S. M. (2003), Sedimentary silica on Mars, Geology, 31, 315 318, doi:10.1130/0091-7613(2003)031<0315:SSOM $>2.0 . \mathrm{CO} ; 2$

McMillan, P. (1984), Structural studies of silicate glasses and meltsapplications and limitations of Raman spectroscopy, Am. Mineral., 69 , 622-644.

Michalski, J. R., M. D. Kraft, T. Diedrich, T. G. Sharp, and P. R. Christensen (2003), Thermal emission spectroscopy of the silica polymorphs and considerations for remote sensing of Mars, Geophys. Res. Lett., 30(19), 2008, doi:10.1029/2003GL018354

Milliken, R. E., et al. (2008), Opaline silica in young deposits on Mars, Geology, 36, 847-850, doi:10.1130/G24967A.1.

Ming, D. W., et al. (2006), Geochemical and mineralogical indicators for aqueous processes in the Columbia Hills of Gusev crater, Mars, J Geophys. Res., 111, E02S12, doi:10.1029/2005JE002560.

Minitti, M. E., C. M. Weitz, M. D. Lane, and J. L. Bishop (2007), Morphology, chemistry, and spectral properties of Hawaiian rock coatings and implications for Mars, J. Geophys. Res., 112, E05015, doi:10.1029/ 2006JE002839.

Morris, R. V., et al. (2000) Acid sulfate alteration products of a tholeiitic basalt: Implications for interpretation of Martian thermal emission spectra, Lunar Planet. Sci., XXXI, Abstract 2014

Morris, R. V., T. G. Graff, S. A. Mertzman, M. D. Lane, and P. R. Christensen (2003), Palagonitic Mars from rock rinds to dust: Evidence from visible, near-IR, and thermal emission spectra of poorly crystalline materials, Lunar Planet. Sci., XXXIV, Abstract 1874 .

Morris, R. V., et al. (2005), Hematite spherules in basaltic tephra altered under aqueous, acid-sulfate conditions on Mauna Kea volcano, Hawaii: Possible clues for the occurrence of hematite-rich spherules in the Burns formation at Meridiani Planum, Mars, Earth Planet. Sci. Lett., 240, 168 178, doi:10.1016/j.eps1.2005.09.044

Mustard, J. F., et al. (2008), Hydrated silicate minerals on Mars observed by the Mars Reconnaissance Orbiter CRISM instrument, Nature, 454 305-309, doi:10.1038/nature07097.

Naughton, J. J. (1980), Composition of come components in gas collected during the 1977 eruption at Kilauea, Hawaii, J. Volcanol. Geotherm. Res., 7, 319-322, doi:10.1016/0377-0273(80)90035-9.

Newman, S., E. M. Stolper, and S. Epstein (1986), Measurement of water in rhyolitic glasses: Calibration of an infrared spectroscopic technique, Am. Mineral., 71, 1527-1541.

Oguri, Y., R. E. Riman, and H. K. Bowen (1988), Processing of anatase prepared from hydrothermally treated alkoxy-derived hydrous titania, J. Mater. Sci., 23, 2897-2904, doi:10.1007/BF00547465.

Ohlhorst, S., H. Behrens, and F. Holtz (2001), Compositional dependence of molar absorptivities of near-infrared $\mathrm{OH}-$ and $\mathrm{H}_{2} \mathrm{O}$ bands in rhyolitic to basaltic glasses, Chem. Geol., 174, 5-20, doi:10.1016/S0009-2541(00) 00303-X

Ohsaka, T., F. Izumi, and Y. Fujiki (1978), Raman spectrum of anatase, $\mathrm{TiO}_{2}$, J. Raman Spectrosc., 7, 321-324, doi:10.1002/jrs.1250070606.

Perry, R. S., B. Y. Lynne, M. A. Sephton, V. M. Kolb, C. C. Perry, and J. T. Staley (2006), Baking black opal in the desert sun: The importance of silica in desert varnish, Geology, 34, 537-540, doi:10.1130/G22352.1.

Rawal, B. S., and A. R. Cooper (1979), Oxygen self-diffusion in a potassium strontium silicate glass using proton activation analysis, J. Mater Sci., 14, 1425-1432, doi:10.1007/BF00549318. 
Riciputi, L. R., B. A. Paterson, and R. L. Ripperdan (1998), Measurement of light stable isotopes by SIMS: Matrix effects for oxygen, carbon, and sulfur isotopes in minerals. Int'l, J. Mass Spectrom., 178, 81-112, doi:10.1016/S1387-3806(98)14088-5.

Rodgers, K. A., K. L. Cook, P. R. L. Browne, and K. A. Campbell (2002), The mineralogy, texture and significance of silica derived from alteration by steam condensate in three New Zealand geothermal fields, Clay Miner. 37, 299-322, doi:10.1180/0009855023720035.

Sankapal, B. R., M. C. Lux-Steiner, and A. Ennaoui (2005), Synthesis and characterization of anatase- $\mathrm{TiO}_{2}$ thin films, Appl. Surf. Sci., 239, 165170, doi:10.1016/j.apsusc.2004.05.142.

Schiffman, P., R. Zierenberg, N. Marks, J. L. Bishop, and M. D. Dyar (2006), Acid-fog deposition at Kilauea volcano: A possible mechanism for the formation of siliceous-sulfate rock coatings on Mars, Geology, 34, 921-924, doi:10.1130/G22620A.1.

Scholl, M. A., S. E. Ingebritsen, C. J. Janik, and J. P. Kauahikaua (1995), An isotope hydrology study of the Kilauea volcano area, Hawaii, U.S. Geol. Surv. Water Resour. Invest. Rep., 95-4213.

Schwertmann, U., J. Friedl, G. Pfab, and A. U. Gehring (1995), Iron substitution in soil and synthetic anatase, Clays Clay Miner., 43, 599-606, doi:10.1346/CCMN.1995.0430509.

Seelos, K. D., R. E. Arvidson, B. L. Jolliff, S. M. Chemtob, R. V. Morris, D. W. Ming, and G. A. Swayze (2010), Silica in a Mars analog environment: Ka'u Desert, Kilauea Volcano, Hawai'i, J. Geophys. Res., doi:10.1029/2009JE003347, in press.

Shimizu, K., H. Imai, H. Hirashima, and K. Tsukuma (1999), Lowtemperature synthesis of anatase thin films on glass and organic substrates by direct deposition from aqueous solutions, Thin Solid Films, 351 , 220-224, doi:10.1016/S0040-6090(99)00084-X.

Skok, J. R., J. F. Mustard, S. L. Murchie, and M. B. Wyatt (2008), CRISM-OMEGA observations of compositionally distinct crater ejecta in the Syrtis Major region of Mars, Eos Trans. $A G U, 89(53)$, Fall Meet. Suppl., Abstract P43A-1384.

Smallwood, A. G., P. S. Thomas, and A. S. Ray (1997), Characterisation of sedimentary opals by Fourier transform Raman spectroscopy, Spectrochim. Acta Part A, 53, 2341-2345, doi:10.1016/S1386-1425(97)00174-1.

Smets, B. M. J., and T. P. A. Lommen (1982), The leaching of sodium aluminosilicate glasses studied by secondary ion mass spectrometry, Phys. Chem. Glasses, 23, 83-87.

Smith, D. C., and E. A. Perseil (1996), The $\mathrm{Sb}^{5+}+\mathrm{R}^{3+}=2 \mathrm{Ti}^{4+}$ substitution in natural titanites and rutiles from St. Marcel, Aosta Valley, Italy, observed with Raman spectroscopy, paper presented at GeoRaman 96, Nantes, France.

Soule, S. A., K. V. Cashman, and J. P. Kauahikaua (2004), Examining flow emplacement through the surface morphology of three rapidly emplaced, solidified lava flows, Kilauea Volcano, Hawai'i, Bull. Volcanol., 66, 1 14, doi:10.1007/s00445-003-0291-0.

Spadaro, F. R., R. A. Lefèvre, and P. Ausset (2002), Experimental rapid alteration of basaltic glass: Implications for the origins of atmospheric particulates, Geology, 30, 671-674, doi:10.1130/0091-7613(2002) $030<0671$ :ERAOBG $>2.0 . \mathrm{CO} ; 2$.

Squyres, S. W., et al. (2007), Pyroclastic activity at Home Plate in Gusev Crater, Mars, Science, 316, 738-742, doi:10.1126/science.1139045.

Squyres, S. W., et al. (2008), Discovery of silica-rich deposits on Mars by the Spirit rover, Science, 320, 1063-1067, doi:10.1126/science.1155429.

Stolper, E. M. (1982), Water in silicate glasses: An infrared spectroscopic study, Contrib. Mineral. Petrol., 81, 1-17, doi:10.1007/BF00371154.

Tilley, D. B., and R. A. Eggleton (2005), Titanite low-temperature alteration and Ti mobility, Clays Clay Miner., 53, 100-107, doi:10.1346/ CCMN.2005.0530110

Tosca, N. J., S. M. McLennan, D. H. Lindsley, and M. A. A. Schoonen (2004), Acid-sulfate weathering of synthetic Martian basalt: The acidfog model revisited, J. Geophys. Res., 109, E05003, doi:10.1029/ 2003JE002218.

Valley, J. W., N. Kitchen, M. J. Kohn, C. R. Niendorff, and M. J. Spicuzza (1995), Strategies for high precision oxygen isotope analysis by laser fluorination, Geochim. Cosmochim. Acta, 59, 5223-5231, doi:10.1016/ 0016-7037(95)00386-X.

White, A. F., and M. F. Hochella (1992), Surface chemistry associated with the cooling and subaerial weathering of recent basalt flows, Geochim Cosmochim. Acta, 56, 3711-3721, doi:10.1016/0016-7037(92)90164-E.

Wyatt, M. B., and H. Y. McSween (2002), Spectral evidence for weathered basalt as an alternative to andesite in the northern lowlands of Mars, Nature, 417, 263-266, doi:10.1038/417263a.

R. E. Arvidson and B. L. Jolliff, Department of Earth and Planetary Sciences, Washington University in Saint Louis, Saint Louis, MO 63130 USA.

S. M. Chemtob, J. M. Eiler, and G. R. Rossman, Division of Geological and Planetary Sciences, California Institute of Technology, Pasadena, CA 91125, USA. (chemtob@gps.caltech.edu) 